\title{
Bibliotecas y Bỉbliotecología en América Latina y el caribe: Un acercamiento
}

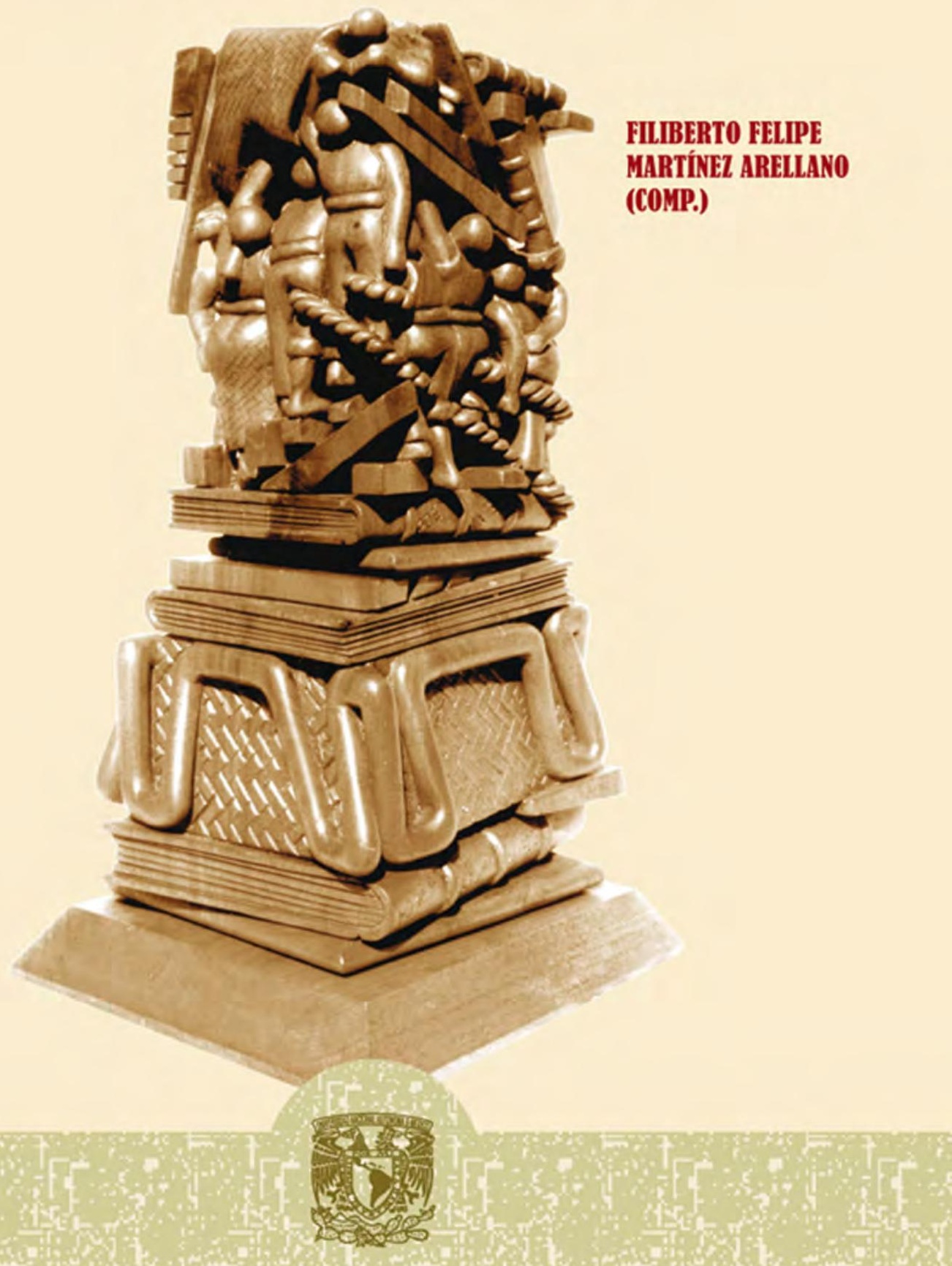




\section{La presente obra está bajo una licencia de:}

\section{http://creativecommons.org/licenses/by-nc-sa/3.0/deed.es MX}

\section{Atribución-No Comercial-Licenciamiento Reciproco 3.0 Unported}

Eres libre de:

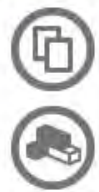

copiar, distribuir y comunicar públicamente la obra

hacer obras derivadas

Bajo las condiciones siguientes:

Atribución - Debes reconocer la autoría de la obra en los términos

especificados por el propio autor o licenciante.

No comercial - No puedes utilizar esta obra para fines comerciales.

Licenciamiento Reciproco - Si alteras, transformas o creas una obra a

partir de esta obra, solo podrás distribuir la obra resultante bajo una licencia

igual a ésta.

\section{Esto es un resumen fácilmente legible del: texto legal (de la licencia completa)}

\section{En los casos que sea usada la presente} obra, deben respetarse los términos especificados en esta licencia.

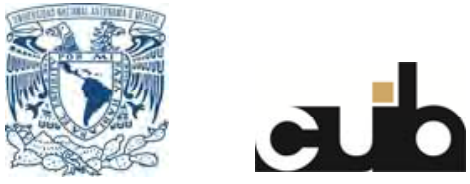


Bibliotecas y Bibliotecología en América Latina y el Caribe: Un acercamiento 
Bibliotecas y Bibliotecología en América Latina y el Caribe: Un acercamiento

\author{
Compilador \\ Filiberto Felipe Martínez Arellano
}

Universidad Nacional Autónoma de México 2007 


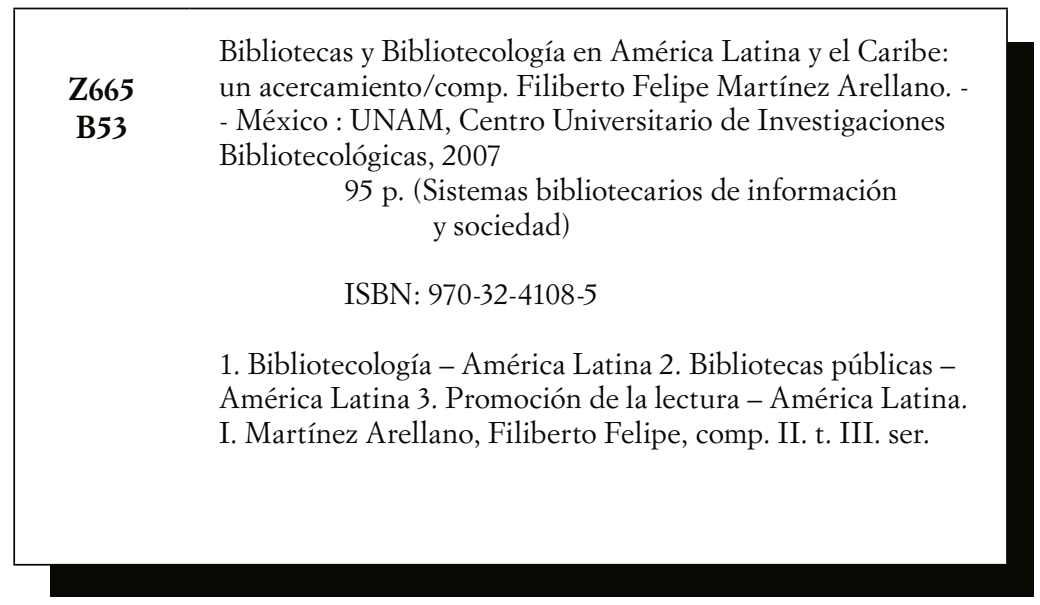

Diseño de portada: Mario Ocampo Chávez

Mixtecs Overcoming, 54x27x21 cm, 1997

(cedro rojo y nogal) Noel López Carrizal

Primera Edición 2007

DR (c) Universidad Nacional Autónoma de MéXico

Ciudad Universitaria, 04510, México D.F.

Impreso y hecho en México

ISBN: 970-32-4108-5 


\section{Contenido}

INTRODUCCIÓN. . . . . . . . . . . . . . . . . . . . . . . . 1

Filiberto Felipe Martínez Arellano

LA SOCIEDAD DE INVESTIGACIONES BIBLIOTECOLÓGICAS DE ARGENTINA. . . . . . 5

Stella Maris Fernández

THIS IS THE LRC: A CASE STUDY OF AN AV INFORMATION

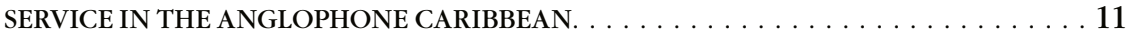

Elizabeth F. Watson

LAS BIBLIOTECAS DE COMFENALCO EN MEDELLÍN Y SU

COMPROMISO CON LA FORMACIÓN DE LECTORES. . . . . . . . . . . . . . . . . . 21

Gloria María Rodríguez Santa María

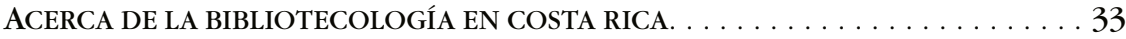

Alice Miranda

LA RED NACIONAL DE BIBLIOTECAS PÚBLICAS DE MÉXICO. . . . . . . . . . . . 53

Filiberto Felipe Martínez Arellano y

Alejandra Martínez Del Prado

LA LECTURA EN LA REGIÓN DE AMÉRICA LATINA Y EL CARIBE. . . . . . . . . . . . . 67

Elsa M. Ramírez Leyva

EDUCACIÓN BILINGÜE INTERCULTURAL Y SERVICIOS

BIBLIOTECARIOS EN LOS PUEBLOS INDÍGENAS DEL PERÚ. . . . . . . . . . . . . . 81

César Castro Aliaga 



\title{
Introducción
}

\author{
Filiberto Felipe Martínez Arellano
}

$\mathrm{E}$

125 de marzo de 2006, la Biblioteca Pública "Gobernador Menezes Pimentel" del estado de Ceara, Brasil, celebró el 139 aniversario de su fundación. Con tal motivo, esta institución, con el apoyo de la Facultad de Biblioteconomía de la Universidad Federal de Ceara, el Consejo Regional de Biblioteconomía (CRB3) y la Asociación de Bibliotecarios de Ceara, organizó una reunión académica titulada "La situación del profesional de la información en la sociedad contemporánea". A este evento académico, también fuimos invitados los miembros de Comité Permanente de la Sección de América Latina y el Caribe de la Federación Internacional de Asociaciones Bibliotecarias e Instituciones (IFLA/LAC), quienes pertenecemos a distintos países de esta región.

En este evento académico, los miembros de IFLA/LAC presentamos una serie de documentos sobre la situación de las bibliotecas, particularmente las bibliotecas públicas, así como sobre la lectura y otros aspectos relacionados con el desarrollo de la Bibliotecología y los Estudios de la Información en América Latina y el Caribe. Teniendo en cuenta que la literatura referente a la problemática de las bibliotecas y de la Bibliotecología en América Latina y el Caribe necesita ser incrementada y que el contenido de los documentos presentados en dicha 
reunión podría apoyar el conocimiento de nuestra región, se consideró pertinente compilar y publicar los documentos que conforman esta obra.

En primer lugar, Stella Maris Fernández de Argentina presenta un documento en donde expone las razones del surgimiento de la Sociedad de Investigaciones Bibliotecológicas de ese país. Señala que el escaso desarrollo en Argentina de la investigación en Bibliotecología, así como la necesidad de apoyarla e incentivarla, motivó la creación de la Sociedad de Investigaciones Bibliotecológicas, una entidad privada sin fines de lucro, dedicada a la investigación en este campo del conocimiento. Asimismo, en su documento hace referencia a los objetivos de esa institución, así como a sus actividades principales y publicaciones.

Elizabeth F. Watson presenta en su contribución a esta obra, la gama de servicios audiovisuales que el Centro de Recursos de Aprendizaje (Learning Resource Centre, LRC) de la Universidad de las Antillas (The University of the West Indies), con sede en Bridgetown, Barbados, ofrece a los estudiantes y profesores de esa institución para apoyar sus actividades de enseñanza, aprendizaje, investigación y difusión. En su documento se abordan diversos aspectos relacionados con el desarrollo de colecciones, el amplio rango de formatos que se coleccionan, así como el tipo de servicios que se proporcionan.

Gloria María Rodríguez Santa María escribe sobre las experiencias de la Red de Bibliotecas Públicas de COMfEnAlCo en la ciudad de Medellín, Colombia. Las acciones presentadas en su documento parten de la base de que el reto de la biblioteca pública es salir en busca del lector y éstas se exponen en cuatro grandes campos: actividades dirigidas a multiplicar las posibilidades de acceso a los libros; actividades de formación con padres de familia, maestros y jóvenes, con el fin de crear ambientes propicios para la lectura; actividades de animación a la lectura y divulgación cultural, así como actividades relacionadas con los medios de comunicación.

En su colaboración, Alice Miranda nos presenta una amplia y detallada descripción de diversos aspectos de las bibliotecas y la Bibliotecología costarricense. Aborda la historia, desarrollo y situación actual de las bibliotecas públicas. También hace referencia a las bibliotecas escolares y a las infantiles, sin dejar de lado a las bibliotecas universitarias. 
De esta manera, su documento presenta un panorama completo de la historia y el desarrollo de la educación bibliotecológica en Costa Rica.

Filiberto Felipe Martínez Arellano y Alejandra Martínez del Prado hacen referencia en el documento con que contribuyen a esta obra al surgimiento, desarrollo y actividades principales de la Red Nacional de Bibliotecas Públicas de México, en la que han tenido lugar una serie de esfuerzos para lograr la integración y actualización de las bibliotecas que conforman esta red, lo cual no ha sido una tarea fácil. Señalan que la situación actual de las bibliotecas públicas en México es totalmente diferente a la existente hace veinte años, aunque todavía queda mucho trabajo por hacer, por lo que los bibliotecarios tienen que redoblar sus esfuerzos para seguir apoyando a este tipo de biblioteca en ese país.

Elsa M. Ramírez Leyva aborda el tema de la Lectura en los países de América Latina y el Caribe, señalando que éste no ha dejado de ser considerado como uno de los problemas prioritarios de la región. Hace referencia a las causas de esta problemática y a diversas alternativas que se han planteado con el fin de buscarle solución, dada la importancia de la lectura como instrumento para la inclusión social y como un factor básico para el desarrollo social, cultural y económico de nuestros países. En su documento también se hace referencia al proyecto "Encuesta Internacional de Lectura para la Región de América Latina y el Caribe", el cual forma parte de una iniciativa global de la Sección de Lectura de la IFLA.

Finalmente, aunque no por eso menos importante, César Castro Aliaga en su documento "Educación bilingüe intercultural y servicios bibliotecarios en los pueblos indígenas del Perú" hace referencia a las experiencias sobre servicios bibliotecarios en los pueblos indígenas de ese país. Señala que los servicios bibliotecarios para las comunidades indígenas en América Latina están relacionados estrechamente con proyectos de carácter educativo, específicamente con la educación bilingüe intercultural. Por lo anterior, la promoción de servicios bibliotecarios no debiera desaprovechar el espacio que ofrece la educación bilingüe intercultural, la que actualmente cuenta con amplio apoyo político y social en la mayoría de los países de la región. 
Los interesados en la investigación y el estudio de las bibliotecas y la Bibliotecología en América Latina y el Caribe, podrían argüir que en esta obra hace falta la información y los datos referentes a la situación en otros países que conforman esta región; sin embargo, los documentos que se incluyen en esta publicación representan un primer acercamiento a la investigación sobre estas temáticas. Por lo anterior, es deseable que además de servir como una obra para el conocimiento de las bibliotecas y de la Bibliotecología en esta región, puede ser un elemento de motivación para ampliar la investigación sobre esta temática y con ello poder conocer de mejor forma y coadyuvar a los solución de los problemas que en materia de bibliotecas y lectura enfrentan los países latinoamericanos y del Caribe. 


\title{
La Sociedad de Investigaciones Bibliotecológicas de Argentina
}

\author{
STElla MARIS FernÁNDEZ \\ Sociedad de Investigaciones Bibliotecológicas, Argentina
}

$\mathrm{E}$

1 convencimiento de que era necesario apoyar e incentivar la investigación en el área de la Bibliotecología, la Documentación y las Ciencias de la Información, dado su escaso desarrollo en Argentina, motivó que en 1998, al jubilarme como Directora del Instituto de Investigaciones Bibliotecológicas de la Facultad de Filosofía y Letras de la Universidad de Buenos Aires, creara la Sociedad de Investigaciones Bibliotecológicas, una entidad privada sin fines de lucro, dedicada a la investigación en este campo del conocimiento en Argentina, de la que actualmente soy su Presidenta.

Es una verdad innegable que para el avance de una disciplina, es indispensable la investigación en todas sus áreas de estudio, actividad de fundamental importancia hoy en día ante las aceleradas transformaciones y cambios que caracterizan a esta sociedad denominada en formas diversas: Sociedad de la Información, Sociedad del Conocimiento, Sociedad Inteligente, etcétera. Una investigación que no sólo contemple el presente y mire al futuro, sino que también incluya una mirada retrospectiva hacia el pasado, pues los límites de la investigación son elásticos e indefinidos. 
La investigación en el área de la Bibliotecología, la Documentación y las Ciencias de la Información, está muy poco desarrollada en Argentina, hecho preocupante si se tiene en cuenta que en casi todo el país existen escuelas que forman bibliotecarios, varias de ellas de nivel universitario, oficiales y privadas, donde se otorgan licenciaturas y en algunas de ellas el doctorado, al margen de también existir la posibilidad de cursar el doctorado en otros países; asimismo, que la función de la Universidad es propiciar la investigación y que un principio esencial de la Universidad es la relación docencia-investigación, "dos caras de una misma moneda", pues en tanto la docencia propaga la metodología y los hechos tal como se van produciendo a varios niveles, el conocimiento adquirido y dominado prepara el camino para el nacimiento y desarrollo de nuevas ideas, y a su vez la investigación, al reorganizar los conocimientos, tiene una función activadora y hasta revolucionaria que tiende a dar fe del progreso.

De acuerdo con lo expresado anteriormente, surge entonces la interrogante: ¿Por qué hay tan poca investigación en esta área del conocimiento? Las causas son diversas. En principio, se es investigador por vocación, no porque la investigación permita obtener un rédito económico. El investigador no espera rédito económico, sólo la satisfacción de haber seguido un camino, realizar un descubrimiento, haber satisfecho una curiosidad, una aspiración; la investigación, en casi la totalidad de los casos, sólo le reporta satisfacciones personales.

En líneas generales, el espíritu de investigación entre nuestros profesionales está ausente, aunque también es verdad que no se les ha preparado para ello y que se ofrece una enseñanza cada vez más simplista, de menores exigencias, al punto que se ha eliminado, en algunos casos, hasta la elaboración de la tesis de licenciatura, lo que podría despertar el interés por investigar en un tema determinado. Por otra parte, los mismos profesores tampoco promueven o incentivan la investigación; mal podrían promover aquello para lo cual ni ellos mismos manifiestan, en general, un gran interés. 
Contribuye a esta falta de interés la dificultad para publicar un trabajo, aunque también es cierto que casi no hay publicaciones especializadas, pero tampoco se presentan trabajos para publicar. El profesional bibliotecario aparece entre nosotros como un profesional preocupado por su métier, por el aspecto técnico, obsesionado en estos momentos por la computación e Internet, considerando a ambas como un eje en su tarea más que como un simple instrumento. Su asistencia a cursos de perfeccionamiento se orienta siempre hacia este tipo de actividades y por ello, esas generalmente son las temáticas de los cursos. En realidad no hay una frecuente, rica y variada oferta de cursos de posgrado. Curiosamente, pese a que trabaja continuamente con libros y documentos, se siente más inclinado a manipularlos para responder a los intereses y necesidades de los usuarios, que para entregarse a su lectura y profundizar en otros aspectos de su profesión. Además, su formación se ha visto viciada al estudiar con fotocopias de libros, de capítulos de libros y hasta de fragmentos de éstos, de los cuales en ocasiones hasta ha llegado a ignorar a que publicación pertenecen, en vez de manejarse directamente con los libros.

Por otra parte, las instituciones oficiales brindan poco apoyo económico para investigar, en principio, porque a esas instituciones no les interesan estas temáticas y prefieren brindar apoyo, aunque de igual modo, muy limitado, a otras orientaciones. También es cierto que en cierto sentido, la educación en general, responsabilidad del Estado, se encuentra en crisis.

Es por ello también que muy pocos siguen el doctorado y en consecuencia, no se presentan tesis. La preparación del doctorado es una fase decisiva en la formación del futuro docente-investigador, ya que conduce al adiestramiento en el método científico y a la adquisición de una sólida formación científica. Esta formación, como la realización de seminarios, son prácticas esenciales en tanto obligan a la lectura de publicaciones importantes y especializadas, a preparar trabajos escritos y a exponerlos en forma adecuada, sometiéndose a la crítica de los colegas, escuchando sus ideas y comentarios. Influye también, en menor medida, el hecho de que los bibliotecarios se ven absorbidos por la necesidad de atender a su subsistencia y que los bajos sueldos les obligan a desempeñarse a veces hasta en más de un trabajo. 
Es evidente además, que una sociedad que va formándose bajo la imagen de la computadora, que va simplificando sus esfuerzos y automatizando al individuo, no es la más propicia para crear un clima favorable para la investigación. Proporciona medios y recursos pero no desarrolla la capacidad de reflexión, de crítica, de asociación de ideas, de organización de conocimientos; se aleja cada vez más del precepto bíblico "ganarás el pan con el sudor de tu frente", lo que parafraseando en el terreno del trabajo intelectual implica "avanzarás más con el ejercicio de tu mente", o dicho con las palabras de Ramón y Cajal, "cada uno es escultor de su propio cerebro". La ciencia, como el arte, exigen esfuerzo constante, dedicación, sacrificio.

Como resultado de ello, la literatura bibliotecológica nacional es casi inexistente. En los últimos años, algunas instituciones privadas, haciéndose cargo de esta situación y con enorme, desinteresado y personal esfuerzo, tratan de llenar ese vacío, tanto en lo relativo a la formación como a la investigación y a la publicación. Lamentablemente, el esfuerzo de esas instituciones, por sus características, por deberse al impulso y al esfuerzo de quienes las dirigen, corren el riesgo de una vida breve.

De esta manera surgió la Sociedad de Investigaciones Bibliotecológicas (SIB), cuyos objetivos son:

- Promover la investigación en el campo de la Bibliotecología, la Ciencia de la Información y disciplinas afines.

- Difundir el resultado de investigaciones a través de publicaciones.

- Contribuir mediante comunicaciones, conferencias y cursos a la puesta al día en esa área del conocimiento y al enriquecimiento cultural y profesional.

- Editar una revista en la que participen profesionales y estudiantes avanzados nacionales y del extranjero.

- Mantener vínculos con instituciones nacionales y extranjeras.

La SIB edita una revista, Infodiversidad, cuyo título precisa su alcance, tal y como se aclaró en su primer número:

"La infodiversidad - en palabras de Estela Morales - es pluralidad, es rescate, es conservación, es disponibilidad y libre acceso a la información. 
La infodiversidad es el conjunto de acciones y funciones que permiten y aseguran al ser humano vivir en un ambiente de fuerzas y productos sociales que lo enriquecen con diversidad de ideas y pensamientos del pasado, del presente, del norte y del sur, de oriente y occidente que le dará equilibrio en su vida como individuo y como parte de un grupo social. La infodiversidad es la difusión de múltiples y diversas manifestaciones en la generación y creación de la información, la defensa de la convivencia de los diferentes tipos de información y a su vez la conservación de ideas y del pensamiento del hombre de todos los tiempos".

El título señala pues, las líneas de la revista, la que dentro de esta área del conocimiento está abierta a la difusión de ideas sobre temas del pasado, del presente, del país, de América Latina y del mundo en general. Conforman su cuerpo artículos de autores latinoamericanos -brasileños, mexicanos, venezolanos, argentinos, etcétera-, reseñas de publicaciones y un noticiero con aquellas noticias relacionadas con temas que puedan ser de interés. Su periodicidad es anual y conforman su Comité Asesor figuras bibliotecarias de gran prestigio, presidiéndolo Josefa E. Sabor, importante figura bibliotecaria argentina conocida en toda América Latina. Se han editado ya nueve volúmenes y está listo para prensa el décimo, acompañado de un índice de todos los números

La revista ha sido muy bien recibida en toda Latinoamérica. Aparece mencionada en el Hispanic American Periodicals Index (HAPI), en Contenidos Corrientes (SISBI), en Información Bibliotecológica Latinoamericana (INFOBILA), en Latindex y pertenece a la red AlyC.

La Sociedad ha realizado numerosas conferencias, presentaciones de libros y ha organizado un Simposio sobre la Biblioteca Escolar. Actualmente, todos los segundos sábados de cada mes, su presidenta, conjuntamente con la hija del poeta Leopoldo Marechal, participan en la Peña del Libro "Trenti Rocamora" en reuniones sumamente exitosas en las que se tratan temas relacionados con librerías y editoriales, así como otros vinculados al plagio y al derecho a la libertad de expresión. La Peña del Libro ha cumplido ya tres años de existencia, cuya historia quedó plasmada en el libro de mi autoría Historia de una Peña. La Peña del Libro Trenti Rocamora. 
La Sociedad ha editado, desde su creación en 1998, nueve años a la fecha, doce libros, además de los nueve números de su revista. Si bien como expresé anteriormente, la vida de estas instituciones, por sus características va ligada a la vida de sus fundadores, también es cierto que cumplen un objetivo, dejan un camino abierto; obran en cierta medida como un revulsivo en medio de la apatía reinante y son un exponente de que cuando se quiere, se puede hacer algo, aunque no sea más que para servir de ejemplo. 


\title{
This is the LRC: a case study of an AV information service in the Anglophone Caribbean
}

\author{
ELIZABETH F. WATSON
}

Learning Resource Centre

The University of the West Indies Bridgetown, Barbados

\section{INTRODUCTION}

The University of the West Indies (UWI) is one of three regional universities in the world. A regional university differs from

other universities in that it seeks to cater to the tertiary level educational needs of a group of countries located within a specific geo-political space. Established in 1948, the three campuses of the UWI in order of their establishment are Mona in Jamaica (1948), St. Augustine in Trinidad (1960) and Cave Hill in Barbados (1963). The UWI serves 15 countries in the English-speaking Caribbean ${ }^{1}$. These states were either former colonies of Britain or territories that still have a formal link with that metropolitan country.

The Cave Hill Campus has a student population of approximately 5,000 and 350 full-time academic, professional and senior administrative staff. A variety of undergraduate, postgraduate, certificate

1 The states served by the UWI are Anguilla, Antigua \& Barbuda: The Bahamas; Barbados; Belize; The British Virgin Islands; Cayman Islands; Dominica; Grenada, Carriacou and Petit Martinique; Jamaica; Montserrat; St. Kitts \& Nevis; St. Lucia; St. Vincent \& the Grenadines; and, the Republic of Trinidad \& Tobago. 
and diploma programmes in the Faculties of Humanities and Education, Law, Physical and Chemical Sciences and Social Sciences are offered on this campus of the UWI. Medicine is offered through the island's main hospital, located on the outskirts of the island's capital, Bridgetown, some distance away from Cave Hill. As the Faculties of Law and Medical Sciences have their own libraries, the primary service cohorts of the Learning Resource Centre (LRC or the Centre) are the Faculties of Humanities and Education, Physical and Chemical Sciences and Social Sciences.

At its establishment the LRC had two sections - an Information Resource Unit (IRU) and an Educational Media Production Unit which includes a hardware pool to provide the equipment required to unlock the data held in the various $\mathrm{AV}^{2}$ formats acquired by the LRC. Since then, the LRC has been expanded to include an Instructional Development Unit which seeks to help faculty members develop their andragogical skills. This paper examines the role and contribution of the IRU to the academic life of its host community, the Cave Hill Campus.

\section{WHAT IS THE LRC?}

Established in 1979, the mandate of the Centre is to provide a range of audiovisual services to support the teaching, learning, research and outreach activities of the campus. The uniqueness of the LRC is demonstrated by the absence of counterpart units on other campuses of the UWI. In addition, no mirror units have been identified in other Third World universities.

The overarching mission of the LRC is to improve the quality of teaching by faculty and to enhance opportunities for learning and research. All LRC activities and functions are tailored to meet this two-

2 The term AV refers to audiovisual materials, sometimes also called non-print or non-book materials. AV materials cover a gamut of products all of which have at least a visual component. AV materials may include sound and motion. For the purposes of this paper, the term AV covers those items so designated in the AACR2 cataloguing rules. 
fold objective. All of the LRC's activities are guided by the curricular offerings and developments undertaken by the campus, locking the activities of the IRU into the academic programmes and programming at Cave Hill. This philosophy underpins the IRU's collection development activities, the range of formats it collects, the type of services it provides and its relationship with the rest of the campus.

\section{COLLECTION DEVELOPMENT}

\section{Scope}

The scope of the collection is guided by the range of courses offered on the campus as well as by the availability of appropriate titles on the commercial market. The collection covers a range of subject areas such as Cultural Studies, Education, Film Studies, Belles Arts, History, Languages and Literatures in the Humanities, Biology, Chemistry, Computing, Mathematics and Physics in the Physical and Chemical Sciences; as well as Economics, Government, Management, Politics, Social Work and Sociology in the Social Sciences. These however are merely broad categories. Within each of these subjects/disciplines items referring directly to specific aspects and topics are acquired as necessary and available.

In addition to purchasing titles that specifically support curricular offerings, the IRU also acquires general interest items. Thus, in addition to educational titles, the IRU's collection includes documentaries and feature length films which its clientele would find useful, interesting and stimulating. Also impacting on the IRU's acquisition policy is a general understanding within the UWI that its information providers will acquire any Caribbean material which becomes known to them. Thus, the IRU purchases any AV programme on any aspect of the Caribbean that comes to its attention. This policy recognises that while a specific Caribbean title may not directly relate to the curriculum that such a title has the potential to be of some significance either programmatically or with respect to the heritage of the region. 


\section{Selection}

In addition to the professional staff of the IRU employing the general principles of collection building known to academic librarians, faculty members are encouraged to recommend suitable titles for purchase. Students, especially those engaged in research are also sources of identifying suitable titles for purchase. Thus, the material selection policy of the IRU is quite liberal and democratic. A cardinal issue in the selection process however is whether the material is pitched at the appropriate academic level. Another consideration is whether the material enhances and enriches the curriculum in some way. This issue does not require a title to dovetail with the programme as taught on the campus - it may, for example, discourse a topic from another perspective thereby triggering discussion and debate, activities which are integral to the academic process.

\section{Formats}

The range of formats acquired by the IRU is dependent on the appropriateness of the material's content and also if the IRU has the required hardware to decode the format to be purchased. Experience and commercial trends have dictated which formats populate the IRU's collection. For example, until recently, VHS video tapes were the preferred format for releases that combined movement with sound. DVDs are now the preferred release format for such materials and therefore the LRC has had to develop a pool of DVD soft and hardware holdings. The video collection is approximately 3,000 titles while the DVDs total 275.

While the national video standard is NTSC (American), because of the range of the campus' curriculum and sources from which it acquires video materials, the IRU also purchases video tapes released in the PAL (British) and SECAM (continental Europe) standards. In order to utilize these formats as video standards are incompatible with each other, the LRC owns the appropriate hardware for each video recording system. DVD recording systems are similarly segmented but at this 
time the LRC only has products which are compatible with the standards used in the Unites States of America. The LRC will acquire, as necessary, other DVD hardware.

CD-ROM and other interactive technologies have placed at the disposal of production houses alternative and enhanced formats for educational materials. As appropriate releases in these formats become available, they will be acquired by the IRU. In addition to providing motion with sound these interactive technologies allow students to become active participants in the learning process, rather than merely passive users. The IRU's CD-ROM holdings currently stand at 142 .

The IRU's collection of sound carriers is extensive and includes audio cassettes, audio tapes, records ( $45 \mathrm{rpm}$ and 33 a discs) and CDs. The record collection is particularly important as it represents the sonic heritage of the region, mainly calypsos and folk songs many of which are no longer available on the market. As a region steeped in the oral tradition such recordings are important containers of the region's patrimony and represent valuable primary source 'documents' on the region's history/ies, culture/s and society/ies. The number of sound carriers held by the LRC totals 6,048.

The collection also includes a range of graphic items such as glass slides, photographs and postcards. These are of considerable historical value as many of them date from the early decades of the last century. These images, numbering around 1,500, provide tangible evidence of the Caribbean of a bygone times and images of life styles that are no longer evident or practised. One of the questions frequently asked of the IRU relates to the cost of AV materials. While some individual some items are expensive, as they can be used by many people at the same time, the cost-per-user and use is reduced. In addition, as technology develops and more titles are available and purchased by similar units, many AV items are cheaper then their print counterparts, e.g. a video or a DVD of a Shakespeare play can be purchased for US\$19.95, whereas the print version of the same play sells for at least US $\$ 10$ more. Thus, AV materials are a cost effective way to provide academic information. 


\section{Other acquisition issues}

The distribution of AV materials is completely different from that which operates for books. Individual production companies determine who or which company will have the right to distribute its products. Additionally, production distribution rights are accorded on the basis of geography. Thus, if a company has not be awarded the right to distribute a product to Barbados it is not allowed to sell the material to the IRU even if it is much closer than that which has been awarded the distribution right for the island. This can be problematic because the Caribbean is often clustered with Latin America for distribution rights, however there are several impediments embedded in this arrangement. These include:

1. Commercial trading arrangements between Latin America and the Anglophone Caribbean are not well developed, therefore the shipment of goods between these two regions are prone to long delays;

2. Because these trading arrangements are not well developed, the movement of goods between these two areas can be quite costly;

3. Many of the countries in both of these regions have currencies prone to instability, therefore payments for goods and services are affected by currency fluctuations and uncertainties; and

4. Differences in linguistic heritages and practice are the source of some stain on communication for business purposes.

While these are not core library activities they have a considerable impact on how any AV library service develops and operates within the Anglophone Caribbean.

\section{TECHNICAL SERVICES}

As the campus has an union catalogue, cataloguing and classification processes are governed by what obtains in the campus' Main Library, 
thus the AACR 2 cataloguing rules and the LC system of classification are used. As the UWI's information providers (of which the IRU is a part) are members of the OCLC consortium, the IRU is also governed by the contractual agreements between the UWI and OCLC. Because $\mathrm{AV}$ items cannot be browsed like books, cataloguing entries for AV material have to be considerably more detailed than that which obtains for books in order for clients to locate segments of titles that are appropriate to their academic needs.

The UWI has recently installed the purchasing, cataloguing and client services module of the Aleph system. The IRU will ultimately utilize these packages in its service preparation and delivery.

In order to maximise the space constraints of the IRU, materials are stored according to format. Clients are informed of item locations through catalogue entries as each item has its format designation as part of its location symbol and cataloguing details.

\section{USER SERVICES}

Browsing facilities of the video collection are limited as users are able to glean only title, performer and release information from storage boxes. Sound carriers can only be accessed through the catalogue which lists album, track titles and the names of performers. These are usually are sufficient for locating sonic products. Access to graphic titles is provided through browsing privileges. Where necessary, the required hardware is provided in order to facilitate use of the IRU's collection.

Because of space constraints, user demands and single title holdings, access is provided on a first-come-first served booking basis. Academic staff are allowed to borrow up to three items for three days materials they intend to use in their class. This enables them to preview titles and prepare the andragogical experience they are planning. Students are not allowed to borrow any of the IRU's collection unless it is to be used in a class as part of a class project/presentation. There is no restriction on the number of times that a member of the Cave Hill community may use any of the IRU's resources. 
Both staff and students are permitted to use the viewing and listening spaces within the IRU. Additionally, IRU items are taken to classes when these are needed for the teaching/learning process. While some of the large teaching spaces around the campus have AV hardware installations, the LRC also has a floating pool of equipment which it delivers-on-demand so that the IRU's collection can be used in course delivery/activities.

\section{IRU'S CONTRIBUTION TO THE CURRICULUM}

The IRU supports curriculum delivery and academic work in many ways. Through its collection the IRU provides a range of enhancement materials which make learning and research more interesting; the AV materials held by the IRU are sources of alternative options for programmatic delivery; and, titles held by the IRU become re/sources for quick revision, e.g. in two hours one can revise an entire Shakespeare play during which one absorbs not only interpretation of the text, but also views costuming, body language, acting techniques and other factors associated with studying a play. Because of the technological techniques available to producers, AV materials are able to reveal many processes that cannot be seen by the naked eye, e.g. the pollination of flowers. Again through technological devices, process that take a long time can be speeded up so that viewers are able to see in a short time span an activity that would take some time to be effected e.g. plant growth and development. The incorporation of technology into academia also allows students to observe a process/activity that is potentially harmful e.g. the use of radioactive substances without unnecessary exposure to such materials. These factors also add to the cost effectiveness of the AV collection and services provided by the IRU of the LRC.

Material held by the IRU is also used to support or become part of the research process. References to IRU owned materials have appeared in or used for illustrative purposes in academic publications produced by members of faculty and professional staff.

In addition to providing academic support services, the holdings of the IRU are used to augment the campus' outreach activities in the 
community and also its public relations initiatives. For example, some of the IRU's cricket holdings will form part of a national exhibition which will be held in March/April 2007 as part of the Cricket World Cup, an international competition between cricket-playing nations which will take place in the Caribbean during that period.

\section{SUCCESSES}

The IRU has been able to demonstrate the important contribution that an AV library service can make to teaching, learning research and outreach. Students find that individual titles are particularly useful in helping them understand a complex issue or assisting with visualising an activity which is outside of their lived experience. Faculty find that AV materials qualitatively add to the teaching/learning experience and researchers find within the LRC research items that are not readily available anywhere else on the island.

Over the IRU's existence, its professional staff has acquired considerable expertise in AV information services. These services have often been accessed by local institutions that have an AV information service issue. This is another way that the IRU contributes to Cave Hill's outreach activities.

\section{Challenges}

While the IRU has had many successes, it nevertheless faces several challenges. Among these is insufficient staffing at all levels. Consequently, the Centre is unable to offer the level of extended opening hours for client access that it would like to provide. The lack of adequate space for client services, storage and administrative activities is another challenge. The lack of sufficient space severely hampers the quality of service that the IRU is able to offer. Once these issues are addressed, the quality and levels of service that the IRU can offer will be greatly improved. These issues can however be only modified at the institutional level. 


\section{CONCLUSIONS}

Over its 28 years of operation, the IRU has become a critical support service for the campus. In addition to enhancing the academic life at Cave Hill, it has contributed to the development of new knowledge through references to its holdings appearing in academic work released by the campus' of faculty and professional staff. Such publications are used not only nationally and regionally but also internationally, giving the campus a presence in academia's global environment.

The existence of such a sophisticated information unit within a developing country also indicates what is possible once some of the necessary resources are made available. The services of the IRU also redound to the benefit of the library and information profession on the island as it demonstrates to the general public a range of alternative professional possibilities and options which traditionally are not past of the tapestries information provision and services. 


\title{
Las bibliotecas de COMFENALCO en Medellín y su compromiso con la formación de lectores
}

\author{
Gloria María Rodríguez SANTA María \\ Departamento de Cultura y Bibliotecas \\ COMFENALCO-Antioquia, Medellín, Colombia
}

$\mathrm{L}$

as acciones presentadas en este documento parten de la base de que el reto de la biblioteca pública es salir en busca del lector y éstas se exponen en cuatro grandes campos: actividades dirigidas a multiplicar las posibilidades de acceso a los libros; actividades de formación con padres de familia, maestros y jóvenes con el fin de crear ambientes propicios para la lectura; actividades de animación a la lectura y divulgación cultural; y actividades con los medios de comunicación. Las experiencias se llevan a cabo en la Red de Bibliotecas Públicas de COMFEnAlCo en la ciudad de Medellín, Colombia.

\section{¿CuÁl es la BIBlioteca PÚBliCA QUE QUEREMOS?}

La biblioteca pública es reconocida e identificada como una de las instituciones que en la sociedad puede contribuir significativamente a realizar acciones concretas para disminuir la desigualdad en el acceso a la información y ampliar la oferta pública y gratuita de materiales de lectura. Pero, lamentablemente, la presencia de bibliotecas públicas en una comunidad no siempre garantiza la formación de una sociedad lectora e informada. Entre las numerosas razones para que esto sea así, especialmente en nuestros países de América Latina, está la poca 
claridad que tienen los políticos, los planificadores sociales y muchas veces los mismos bibliotecarios, al definir para quién, para qué y qué es lo que se quiere con este tipo de biblioteca.

Aunque muchas instituciones bibliotecarias en América Latina se autodenominan bibliotecas públicas, en la práctica parecen ser, y de hecho son, otra cosa: Lo más típico es encontrar en nuestras ciudades la Biblioteca-tarea, aquella que soporta casi exclusivamente los requerimientos académicos de los escolares y los universitarios, en otras palabras, bibliotecas académicas ubicadas lejos de las aulas de clase. También encontramos las Bibliotecas depósito, aquellas que nunca cuentan con presupuesto para renovarse y actualizarse, viven de donaciones que la mayoría de las veces no tienen nada que ver con lo que la comunidad quiere y necesita, y por tanto, van agonizando lentamente. Existen, por otra parte, las Bibliotecas espectáculo, donde sólo se gestiona dinero para apoyar proyectos de animación cultural y actividades recreativas, dejándose al margen las labores alrededor de la lectura y la información. Otras se ocupan casi únicamente de conservar el patrimonio y trabajar con investigadores, estas se pueden denominar Biblioteca memoria. Por último, algo que ha venido surgiendo en mi país en los últimos años: las Bibliotecas-mausoleo, magníficos proyectos arquitectónicos en los que no se tiene en cuenta a las comunidades, que se supone son sus directas beneficiarias, y mucho menos aún se piensa en que hay que diseñar unos servicios acordes con un contexto y una comunidad específica.

No pretendo descalificar el aporte y el trabajo que muchas bibliotecas públicas están realizando en América Latina, y más aún bajo condiciones adversas. Tampoco quiero insinuar que en ciertas circunstancias las bibliotecas públicas no se vean obligadas a cumplir algunas de las tareas que acabo de mencionar; pero no quiero dejar de insistir en que el carácter de biblioteca pública lo imprime una intención clara y decidida de servir de conexión entre el individuo, la lectura, la información y el acceso a las manifestaciones culturales. Y al hablar de individuo, no me refiero únicamente al ya iniciado en los asuntos de la lectura, o sea, a ese grupo de ciudadanos privilegiados que demandan y utilizan los servicios de la biblioteca; me refiero principalmente a esa mayoría de la población que no está inscrita en los 
procesos de educación formal, que no cuenta con otros servicios alternativos donde cubrir necesidades de lectura e información, que no cree que la biblioteca le pueda servir para algo, o lo que es peor, que ignora su existencia y probablemente nunca va a llegar a la lectura, si los libros y los materiales de lectura no van en su búsqueda.

Una biblioteca no es pública sólo por el simple hecho de ofrecer acceso libre a las personas, lo es porque diseña y dirige sus servicios intencionalmente a los distintos segmentos de la población. Incorporar a la dinámica a otros grupos como los obreros, los desempleados, los desplazados, los discapacitados, los adultos mayores, las amas de casa, los niños, los jóvenes desescolarizados, etcétera, es una tarea urgente de las bibliotecas públicas. Esta idea en algunos círculos se tilda de romántica, ortodoxa e innecesariamente costosa; pero es un hecho que si la biblioteca pública continua concentrando su actividad sólo en los estudiantes y los investigadores, pierde la oportunidad de contribuir a compensar las desigualdades sociales y educativas existentes en la sociedad y, por consiguiente, le quedará más difícil coadyuvar en la reducción de los factores de marginalidad, pobreza y segregación, resultantes de la injusticia social y causantes, en gran medida, de los elevados índices de descontento social y conflictos violentos. En otras palabras, continuará siendo una institución alejada de lo que la gente hace y sueña; es decir, seguirá negando al ciudadano.

Es entonces una tarea impostergable pensar en la biblioteca pública desde la heterogeneidad de los usuarios y de las comunidades y no sólo desde la demanda real que atiende actualmente. Una demanda que, entre otras cosas, es fruto de la carencia de infraestructuras bibliotecarias dignas donde las debe haber: la escuela y la universidad.

\section{LA HETEROGENEIDAD: DEL PAPEL A LA ACCIÓN}

La experiencia de trabajo que expondré a continuación, corresponde a COMFENALCO Antioquia, una Caja de Compensación que funciona en Medellín, Colombia y que cuenta con una Red de Bibliotecas Públicas desde 1979. Desarrolla un trabajo local, bajo las circunstancias de una ciudad latinoamericana que poco a poco va superando unas condiciones 
sociales, económicas y políticas complejas, quizás más complejas que las padecidas en la mayoría de las ciudades de la región.

En una sociedad llena de desigualdades, contrastes, e injusticias, el trabajo bibliotecario no puede ser igual, ni siquiera en bibliotecas ubicadas en la misma ciudad. Nuestro trabajo no es de grandes dimensiones en tamaños, la mayoría de las cosas que les contaré se presentan en pequeña escala, realizadas con grupos reducidos, algunas muy experimentales. No todo funciona en todas partes, por esto intentamos que los servicios sean muy ágiles, que permitan variaciones, innovaciones y cambios; ya que las comunidades son distintas y se llega a ellas a través de caminos distintos. Aunque la estructura de la institución bibliotecaria en la cual están enmarcados, es una estructura compleja y muchas veces rígida, intentamos que en el trabajo diario en las bibliotecas de los barrios no se pierda ese toque personal, particular y humano. Como lo sugiere Genevieve Patte, tratamos de mantener pequeñas estructuras insertas en grandes estructuras.

Los diferentes entornos, los barrios donde están ubicadas las bibliotecas, sus condiciones particulares, han ido moldeando y conformando las estrategias que se presentan a continuación. Algunas de ellas tradicionales, y otras propias y originales, nacidas de necesidades específicas. Cada una tiene su propia dimensión y corresponde a una etapa de trabajo que se realiza para acercar al individuo a la lectura y a la información.

Podemos dividir nuestras acciones en relación con la lectura que realizamos desde las bibliotecas de COMFENALCO en cuatro grandes áreas:

1. Actividades dirigidas a multiplicar las posibilidades de acceso a los materiales de lectura entre los diferentes grupos de la comunidad.

2. Actividades de formación con padres de familia, maestros y jóvenes con el fin de crear ambientes propicios para la lectura.

3. Actividades encaminadas a propiciar un acercamiento de las comunidades a los libros y a la lectura mediante las acciones de animación a la lectura y divulgación cultural. 
4. Actividades con los medios de comunicación para motivar a la sociedad en general hacia la lectura.

Actividades dirigidas a multiplicar las posibilidades de acceso a los materiales de lectura entre los diferentes grupos de la comunidad

Partimos de la premisa de que sin materiales de lectura no hay lectores, pero también sabemos que aunque los materiales de lectura son una condición necesaria para formar lectores, su sola presencia no es suficiente para alcanzar este fin. Por tanto, dotar una sala infantil o una juvenil con materiales variados, actualizados y acordes con las necesidades de la comunidad, es básico, pero no es suficiente. Contar con buenos espacios, mobiliario atractivo, horarios adecuados y facilidades de acceso es ideal, pero no es suficiente. Tener personal entrenado y comprometido, es vital, pero tampoco es suficiente. El gran reto de los servicios bibliotecarios frente a la formación de lectores es superar la conformidad de permanecer sólo con ese grupo privilegiado que, por una u otra circunstancia, utiliza y conoce los servicios de la biblioteca, la disfruta y la frecuenta. En otras palabras, nuestro reto es salir en busca del lector.

Por eso intentamos que gran parte de nuestras actividades se realicen en lugares externos a los edificios que ocupan las bibliotecas y que se ubiquen en los sitios que frecuentan los niños y los jóvenes: el parque, la calle, la escuela, etcétera. Algunas de las acciones que se realizan en este sentido son las siguientes:

Las Cajas Viajeras, colecciones de libros que se prestan a las escuelas del radio de acción de las bibliotecas, y a las fábricas y empresas como un servicio para los trabajadores. En estas colecciones que enviamos casi siempre incluimos libros para niños y jóvenes con el fin de que los trabajadores los puedan llevar a sus casas para compartirlos con sus hijos. Los Paraderos Paralibros Paraparques, conocidos como $P P P$, que son un programa de préstamo de libros que se ubica en una estructura metálica en un parque o espacio público. Los programas de lectura callejeros como las Lecturas itinerantes, Lecturas 
de Barrio o Biblioesquina, en los cuales se llevan colecciones a sitios específicos de la comunidad, semanalmente a la misma hora. Algunas veces los programas callejeros se crean para facilitarle materiales de lectura a sectores de la ciudad que no cuentan con bibliotecas, en otras ocasiones surgen para mitigar un poco el problema de las bandas juveniles y los conflictos que se generan entre los habitantes de los distintos barrios, cuando traspasan las fronteras y los limites de su territorio. Los programas que se asocian con festividades y celebraciones de la comunidad como los Biblioparques y los Festivales de Lectura, y los programas con niños de 0 a 6 años a través del programa de gobierno denominado Hogares infantiles comunitarios.

En el 2004 iniciamos, junto con FUNDALECTURA, un programa denominado Leer en familia. En éste trabajamos de la mano del Sistema de Salud y se lleva a cabo luego del nacimiento del bebé, cuando la mamá está aun en la clínica. Consiste en la entrega de una bolsa con un libro infantil, recomendaciones para iniciar al bebé en la lectura, libros recomendados, y el carné de la biblioteca, entre otros. Algunas de estas familias reciben una invitación para asistir luego a la biblioteca con su bebé a talleres y sesiones de lectura. Este programa fue tomado del programa inglés Bookstart.

Con el mismo fin de multiplicar las posibilidades de acceso al libro tenemos el programa de Menú literario, en asociación con dos hoteles. En cada habitación de los hoteles, el huésped encuentra un menú impreso con libros recomendados para leer durante su estadía. En este menú hay libros dirigidos a los distintos miembros del grupo familiar. También el programa Libro Correo, que consiste en el envío mensual de libros a un grupo de padres de familia para que los lleven a sus hijos.

Al comienzo del año escolar, durante todo un mes, se tiene la temporada de intercambio de libros de segunda, la cual se constituye en un lugar de trueque donde los jóvenes pueden llevar los libros usados y cambiarlos por otros. Este programa nació de la experiencia del Banco del Libro en Venezuela. Desde hace tres años se unió a esta iniciativa la Fundación Éxito, la cual lo está impulsando en otras ciudades y apoya con una gran campaña de donación de textos en los almacenes de su cadena en todo el país. 


\section{ACTIVIDADES DE FORMACIÓN CON MAESTROS, PADRES DE FAMILIA Y JÓVENES}

Que los maestros tengan experiencias gratificantes de lectura que los motiven a estimular a sus alumnos y a impulsar proyectos bibliotecarios en sus establecimientos educativos es uno de los propósitos que se persigue en las bibliotecas de COMFENALCO. Con este fin, se ha estructurado un Programa de formación de maestros constituido por cuatro niveles.

Para estimular a educadores y bibliotecarios con sus programas de promoción de la lectura, se les ha creado un evento denominado Acciones de promoción de la lectura: otras voces, en el cual ellos tienen la palabra para contar a la comunidad lo que hacen para fomentar la lectura en sus instituciones. Este programa también cuenta con otro tipo de invitados como periodistas, políticos, que comparten sus experiencias lectoras.

Para los padres de familia y el público adulto interesado en la formación lectora de los más pequeños, se ofrecen unas sesiones mensuales de conferencias denominadas Taller de formación de lectores en el hogar, en las cuales se tratan de manera teórica y práctica algunos asuntos relacionados con la formación de lectores, con temas tales como los libros ilustrados, la poesía infantil, los libros informativos, el cuento y la novela para niños, entre otros.

Asimismo, dirigidos a los adultos, se han diseñado volantes y plegables como la serie Leer toda una aventura, donde se dan recomendaciones y consejos para la iniciación a la lectura en los más pequeños y para la práctica de la lectura en voz alta y la lectura silenciosa.

En 1998 se crearon, en algunas sedes de las bibliotecas, talleres semanales de creación literaria con jóvenes, dirigidos por un poeta reconocido en el medio. Como fruto de este ejercicio permanente se han publicado varias antologías con los mejores escritos de los jóvenes.

Se cuenta con una serie de Seminarios Juveniles para el Fomento de la Lectura, en diferentes bibliotecas y sitios de la ciudad, dirigidos a motivar a los jóvenes que han demostrado interés por el fomento de la lectura y que visitan la biblioteca de manera periódica. De esta forma se les posibilita un acercamiento más formal con el libro y la lectura y se estimula su creatividad y talento. 
ACTIVIDADES ENCAMINADAS A PROPICIAR UN ACERCAMIENTO A LOS LIBROS Y A LA LECTURA MEDIANTE ACCIONES DE ANIMACIÓN A LA LECTURA Y DIVULGACIÓN CULTURAL

Los programas de lectura en voz alta para niños y jóvenes, aunque tienen la misma esencia, presentan nombres diferentes dependiendo del público a quien van dirigidos, así como del lugar y las circunstancias donde se llevan a cabo: Palabras para compartir, para niños pequeños acompañados de sus padres, Menguante literario, para jóvenes y adultos; Lecturas en la Clínica León XIII, para niños hospitalizados; Esperando el doctor, para niños y madres que esperan la atención medica, Lecturas en la cárcel, para mujeres recluidas en prisión, etcétera.

Contamos también en las bibliotecas con clubes de lectores, para jóvenes y adultos que leen durante el año 7 u 8 libros y se reúnen semanalmente para leer y compartir lo leído.

Desde principios de la década de los 90 realizamos una actividad semanal para los adultos denominada Oír-Leer, que es una lectura en voz alta, realizada por locutores de la radio, de fragmentos de novelas, ensayos o poemas, previamente programados para el semestre. En todas las bibliotecas hay programas semanales para niños, jóvenes y adultos con lo mejor del cine mundial, entre ellas están: Niños en el cine, estrellas y estrellas, la cámara lúcida, cinema azul. Estos programas son dirigidos por jóvenes aficionados y conocedores del cine.

Desde 1995 se inició la producción de una serie de exposiciones, a las que me gusta denominar libros murales, aunque no tienen forma de libro. Estas exposiciones se exhiben en las bibliotecas de COMFENALCO y luego circulan gratuitamente por colegios, universidades, casas de la cultura y otras bibliotecas de la ciudad, y se alquilan a empresas y a centros comerciales. Entre ellas cabe destacar las exposiciones relacionadas con los autores, personajes e ilustradores de la literatura infantil y juvenil. El año pasado, como homenaje a los 200 años de nacimiento de Hans Christian Andersen, se realizó una exposición y se hizo un CD para la venta con algunos cuentos del autor.

A partir del respeto y la valoración por lo que le gusta a los jóvenes y como una manera de atraerlos a la biblioteca se realizan los ciclos 
semanales de videoconciertos de rock. Esta experiencia ha propiciado a su vez la concepción y el diseño de una exposición gráfica y mural denominada los instantes del rock.

\section{LOS MEDIOS MASIVOS DE COMUNICACIÓN}

Son muchos los protagonistas que deben intervenir en la formación de lectores. No es un problema exclusivo de la escuela ni tampoco de la biblioteca. Es una suma de múltiples esfuerzos, donde participan la escuela, la biblioteca, la familia, los adultos, el gobierno y los medios de comunicación, entre otros. Conscientes del poder y el impacto que ejercen los medios de comunicación, y de la cantidad de público al que un medio de esta naturaleza puede llegar, se colabora desde hace 15 años en la separata infantil de El Colombiano, el principal periódico de Medellín y el segundo del país. Este medio es utilizado quincenalmente por COMFENALCO para orientar a la comunidad en el vasto mundo de la literatura infantil.

También hemos incursionado en programas de televisión dirigidos a público infantil y juvenil. Estuvimos en el programa Cucaramaca por más de un año con recomendaciones de libros, lecturas en voz alta y otras actividades. El programa se terminó pero fue una buena experiencia que mostró como hacer actividades de promoción de lectura masivas y de impacto

Como una estrategia de divulgación cultural y buscando también generar ingresos que nos ayuden a continuar las actividades emprendidas, se inició un proyecto de producción de artículos culturales para la venta, relacionados con la lectura, el libro y la información. Este proyecto lo denominamos la Vitrina Cultural, el que se constituye en una tienda que ya cuenta con 10 puntos de venta y en donde las personas pueden encontrar camisetas, mugs, almanaques, agendas, gorras, bolsos y diversos tipos de souvenir o regalos relacionados con el mundo de las bibliotecas.

Para terminar, quiero insistir en dos de los factores de éxito en la formación de lectores: la periodicidad y permanencia de las actividades, además de las personas que coordinan o realizan estas actividades. 
Me gusta siempre comparar las acciones de promoción de lectura con las campañas de nutrición. No basta con que un solo día se le reparta a un grupo de niños que sufre de desnutrición un vaso de leche. Si se quiere tener un logro y conseguir un buen resultado en el tiempo, es necesario que las acciones sean continuas e intencionales. La continuidad, la permanencia, son el punto clave de cualquier acción eficaz en la creación de hábitos de lectura. Las actividades ocasionales, como las ferias, las visitas esporádicas de un bibliobus a una escuela, a un caserío o a un barrio marginado, pueden despertar interés, mejorar la opinión pública, pero también pueden generar un sentimiento de frustración si carecen de continuidad.

Los profesionales que están a cargo no sólo de la realización y diseño de las actividades, sino además de la selección y compra de los libros, deben estar preparados, motivados y entusiasmados con lo que hacen. Deben tener un muy buen conocimiento del entorno. En la bibliotecas de COMFENALCO todas las actividades orientadas a poner en contacto a los distintos públicos con los materiales de lectura están administrativamente dependiendo de una coordinación denominada Coordinación de Fomento de la Lectura. Muchas veces los mismos bibliotecarios nos preguntan el por qué de la creación de un área de la biblioteca dedicada a la lectura. La conformación de esta área fue intencional, éramos conscientes que nuestra tarea como bibliotecarios iba más allá de la atención a los usuarios y tenía que ver más con la formación de lectores. Queríamos ser más estratégicos, desarrollar servicios, unificar criterios, llegar a otros públicos alejados de los beneficios de la zona urbana y sobre todo tener espacios para la reflexión y el análisis. Se conformó un equipo interdisciplinario conformado por profesionales de educación, español y literatura, educación pre-escolar, idiomas y Bibliotecología., quienes se hacen cargo de las actividades descentralizadas y las que se realizan en cada una de las sedes de las bibliotecas.

Para terminar, la biblioteca pública no debe desaprovechar ninguna oportunidad para promover la lectura y generar lazos y relaciones entre las personas y los materiales de lectura. Por tanto, todo esfuerzo que se haga en diseñar programas innovadores, en llegar a nuevos grupos, en capacitar al personal, en generar reflexión en torno 
a sus acciones, en divulgar y hacer conocer sus programas, facilitará y preparará el ambiente para que cada día más y más niños y jóvenes inscriban la lectura con naturalidad como otra de sus actividades cotidianas. 



\title{
Acerca de la Bibliotecología en Costa Rica
}

\author{
Alice Miranda \\ Escuela de Bibliotecología, Documentación e Información \\ Universidad Nacional, Costa Rica
}

\begin{abstract}
... una sociedad influyente en la que cada persona sea capaz de crear, acceder, usar y compartir la información y el conocimiento [... ] significa ofrecer a las personas la oportunidad de buscar, recibir y comunicar información e ideas sin ningún tipo de restricciones...

IFLA/FAIFE 2005
\end{abstract}

\section{INTRODUCCIÓN}

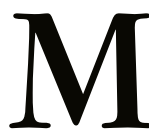

iriam Álvarez Brenes, Nelly Kopper, Efraim Rojas, Elia María Van Patten, Deyanira Sequeira, Manuel Oviedo, entre otros, han sido grandes inspiradores y orientadores del desarrollo de la Bibliotecología en Costa Rica. ${ }^{1} \mathrm{Al}$ interactuar con otros bibliotecólogos han surgido nuevas formas de pensamiento en torno a la cultura bibliotecológica costarricense para innovar en la práctica y en la teoría. Acercar consensos y construir perspectivas integrales constituyen espacios de debate, mejoramiento profesional y aportes a la alfabetización informacional de los costarricenses.

1 Costa Rica está ubicada en el Istmo Centroamericano con una población cercana a los 4.5 millones de habitantes. El área territorial es de $51100 \mathrm{Km}^{2}$. 


\section{BIBLIOTECAS PÚBLICAS}

El origen de las bibliotecas en Costa Rica se remonta a 1879. Según Obregón Lizano, citado por Rodríguez y Méndez (2005), la Biblioteca Pública de San Ramón se funda el 4 de julio de 1879 por el esfuerzo de Don Julián Volio Llorente. Ese mismo año se organiza la "Sociedad Bibliotecaria” y en 1880 la Biblioteca cuenta con aproximadamente 1300 volúmenes. En 1882 tiene lugar un acontecimiento muy relevante para el país, la Iglesia Católica cierra la Biblioteca al censurar algunas de sus obras. En 1890 se crea una nueva biblioteca en Alajuela e inmediatamente se crean la Biblioteca Nacional y las Bibliotecas Públicas de Heredia y Cartago.

En 1890 se nombra a Miguel Obregón Lizano como primer Director General de Bibliotecas, insigne hombre de letras quien le dio un gran aporte a la Bibliotecología costarricense. En ese mismo año se aprueba el Reglamento Oficial de Bibliotecas Públicas.

Aliadas a la bibliotecas públicas nacen las bibliotecas municipales, las cuales se inician en la primera mitad del siglo $\mathrm{XX}$, en concordancia con el Decreto no. 10 del 17 de octubre de 1941, donde el Presidente declaró de utilidad pública la creación de bibliotecas públicas en cada cantón y se le encarga a la Biblioteca Nacional la provisión de libros. Con la Guerra Civil de 1948, algunas bibliotecas se vuelven a cerrar.

Un factor relevante en el desarrollo de las bibliotecas públicas en Costa Rica fue la creación, en 1971, del Ministerio de Cultura, Juventud y Deportes porque las 18 bibliotecas públicas se adscriben a éste. Puede especularse que su finalidad era contar con una mayor cuota de poder en el gobierno, lo que les permitiría mayor visibilidad y fortalecimiento.

Otro avance importante en la construcción de la Bibliotecología costarricense es que en 1974 se creó el Departamento de Bibliotecas Públicas, encargado de coordinar y dirigir las bibliotecas públicas del país. La innovación más notable que introdujo fue el desarrollo de colecciones centralizadas, creación de nuevos instrumentos de trabajo y de una manera modesta, la tecnificación y modernización de las bibliotecas.

En los años 80 se reorganiza la Biblioteca Nacional y se crean las bibliotecas públicas semioficiales, se adquiere un bibliobús y se designa a la Biblioteca Nacional como el centro del sistema. En 1990, al Departamento 
de Bibliotecas Públicas se le denomina Dirección de Bibliotecas Públicas y se integra el SINABI que lo conforman 33 bibliotecas públicas oficiales, 25 bibliotecas públicas semioficiales y un bibliobús.

La misión del Sistema Nacional de Bibliotecas Públicas es: "Promover en forma gratuita el desarrollo intelectual de la población, con el fin de contribuir al desarrollo integral de los ciudadanos y ciudadanas, a través del libre acceso a la información en sus diferentes formas de presentación". Su objetivo general es: "Garantizar el derecho de acceso a la información en igualdad de condiciones a todas las personas, sin ningún tipo de discriminación haciendo de la biblioteca un lugar de todos y para todos" (Costa Rica, Ministerio de Cultura, Juventud y Deportes, 2005, p. 1).

El presupuesto con que se nutre el Sistema proviene del Poder Ejecutivo. En el 2004 fue distribuido de la siguiente manera: un 89\% para recursos humanos, un $0.29 \%$ para servicios, un $3.4 \%$ para colecciones y un $7.4 \%$ para infraestructura (Rodríguez y Méndez, p. 59).

El organigrama del Sistema Nacional de las Bibliotecas Públicas de Costa Rica se muestra a continuación:

Organigrama no. 1

Sistema Nacional de Bibliotecas Públicas

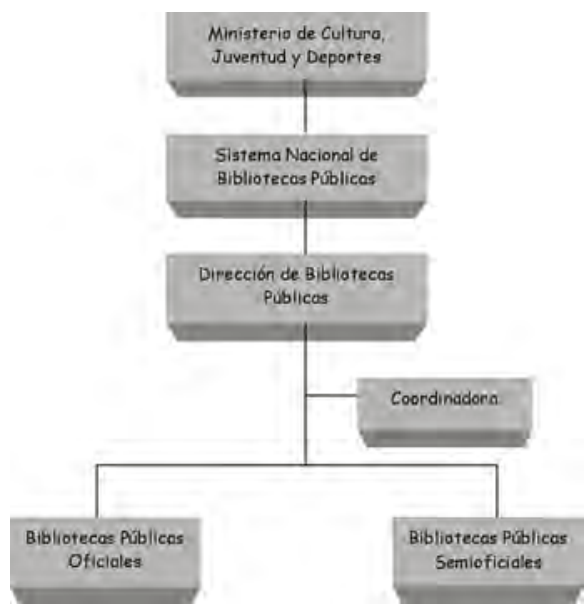

Fuente: Rodríguez, 0. y Méndez, X. (2005). La escolarización de la Biblioteca

Pública, con una propuesta para extender la cobertura de las bibliotecas públicas oficiales a la comunidad. Heredia, C.R. : UNA. p. 63 
Un perfil esquemático de las bibliotecas públicas oficiales de Costa Rica se muestra a continuación:

Cuadro 1: Sistema Nacional de Bibliotecas Públicas

Perfil de las bibliotecas públicas oficiales, por provincia 2004

\begin{tabular}{cccccc}
\hline Provincia & Población & $\begin{array}{c}\text { No. de } \\
\text { Bibliotecas }\end{array}$ & Libros & $\begin{array}{c}\text { Usuario atendido } \\
\text { por trimestre }\end{array}$ & $\begin{array}{c}\text { Promedios de usuarios } \\
\text { por mes }\end{array}$ \\
\hline San José & 1050693 & 11 & 128381 & 143602 & 47868 \\
Alajuela & 659408 & 11 & 125416 & 133248 & 44415 \\
Heredia & 118932 & 2 & 33680 & 26754 & 8918 \\
Cartago & 333924 & 5 & 53078 & 29519 & 11429 \\
Puntarenas & 136327 & 2 & 23210 & 7977 & 2659 \\
Limón & 89933 & 1 & 25500 & 42012 & 14004 \\
Guanacaste & 46703 & 1 & 10710 & 38875 & 12958 \\
\hline Total & 2435920 & 33 & 400025 & 421987 & 142251 \\
\hline
\end{tabular}

Fuente: Rodríguez, 0. y Méndez, X. (2005) La escolarización de la Biblioteca Pública, con una propuesta para extender la cobertura de las bibliotecas públicas oficiales a la comunidad. Heredia, C.R. : UNA.

En este cuadro puede observarse que las bibliotecas públicas atienden un $57 \%$ de la población nacional. Las provincias periféricas cuentan con un $12 \%$ de las bibliotecas públicas del país y sólo un $15 \%$ de los volúmenes de las obras que conforman el acervo documental de este sistema.

El recurso humano de las bibliotecas públicas oficiales de Costa Rica lo constituyen 70 funcionarios, de los cuales el $49 \%$ ocupa un puesto profesional y el $51 \%$ de técnico, según los datos que indican Rodríguez y Méndez.

\section{BIBLIOTECAS EDUCATIVAS}

Las reformas educativas realizadas entre 1960 y 1970 incluyeron la creación de bibliotecas, como apoyo fundamental al desarrollo de la oferta académica. Los promotores de las bibliotecas escolares en Costa Rica fueron Elia María Van Patten y el director de la Biblioteca de la 
Universidad de Costa Rica, profesor Efraim Rojas, quienes han dado un aporte significativo al papel que debe cumplir la biblioteca en el Sistema Educativo Nacional.

En 1972 se celebra el Primer Seminario de Bibliotecas Escolares de Costa Rica y el Primer Curso sobre Bibliotecas Educativas, of recido por la Universidad de Costa Rica. En 1974, Costa Rica contaba con 140 bibliotecas educativas. Para 1975 se propone la creación del Sistema de Bibliotecas Escolares de Costa Rica y en 1977, la OEA financia el sistema. Entre lo que se priorizó está la integración del Sistema en dieciséis núcleos. Los cursos de capacitación los ofrecieron las escuelas de Bibliotecología de la Universidad de Costa Rica y de la Universidad Nacional. En 1990, la OEA finiquitó su apoyo lo que afectó su avance.

El sistema cuenta con un Departamento encargado de su coordinación, desde donde se programan cuatro talleres al año para los diferentes núcleos y un encuentro nacional en coordinación con la Escuela de Bibliotecología y Ciencias de la Información de la Universidad de Costa Rica.

En la actualidad, el personal de las bibliotecas educativas lo conforman cerca de 400 bibliotecólogos con código de biblioteca y 350 docentes maestros con recargo. Dentro de sus funciones se destacan las siguientes:

- Realiza esfuerzos ingentes para dotar a las bibliotecas de recursos bibliotecológicos, electrónicos y equipo audiovisual.

- Coordina con los docentes para conocer las necesidades específicas y para integrarse en la planificación curricular.

- Establece comunicación constante con los estudiantes para informarlos de los servicios que se ofrecen y los últimos recursos que se adquieren.

- Crea vínculos solidarios con las autoridades educativas y sensibilizado sobre sus funciones. (Garmendia, 2005, p. 45)

Los recursos económicos son precarios por lo que su mobiliario no es apropiado y la mayoría de las bibliotecas poseen escasos recursos humanos. El desarrollo de colecciones, en un alto porcentaje, se logra por donación. El procesamiento de la información se inicia con el sellado e inscripción y son pocas las bibliotecas que tienen su colección 
procesada. Sólo cuatro bibliotecas cuentan con catálogo público y algunas de ellas un servicio de catálogo en línea. Ocho se pronuncian a favor de apoyar el proceso de digitalización de los materiales.

Según el estudio realizado por Garmendia (2005), el 81\% de los encargados de las bibliotecas educativas es graduado en Bibliotecología. El 93\% de ellos tiene acceso a las computadoras en su trabajo y el resto está realizando trámites para lograrlo. El acervo documental está organizado por colecciones específicas tales como: general, de referencia, archivo documental, audiovisual y digital. En el 9\% de las bibliotecas se realiza diseminación selectiva de información (DSI).

Los usuarios del sistema lo constituyen los estudiantes, docentes y padres de familia. El uso que le dan a la biblioteca varía entre actividades curriculares, recreativas y como área de trabajo. En la mayoría de las bibliotecas hay programas de inducción sobre el reglamento de la biblioteca y sus servicios. Aplican una metodología participativa que va desde la motivación, pasando por la explicación y llevando lo aprendido a la práctica. En algunos centros educativos realizan tallares tales como: "Taller de búsqueda y localización de información y técnicas de investigación” y "Taller Didáctica del aula basada en las inteligencias múltiples: importancia de la información".

Entre los problemas que se señalan para este sistema destacan el escaso presupuesto y la carencia de una política sobre el papel de la biblioteca en el desarrollo curricular (Garmendia, 2005). Existe un interés constante por parte de la asesora de dichas bibliotecas para que el personal se capacite en forma continua, para lo cual utiliza el recurso de las videoconferencias (Morera, 2006, comunicación telefónica).

\section{BIBLIOTECAS INFANTILES}

Las bibliotecas infantiles surgen en Costa Rica en 1971, como una preocupación de un grupo de damas voluntarias quienes adscriben su iniciativa en la Municipalidad de San José, en la Dirección de Cultura. En la actualidad, la Municipalidad de San José cuenta con siete bibliotecas infantiles, la mayoría de ellas ubicadas en zonas muy conglomeradas y de riesgo social. 
La metodología que se aplica en todas ellas está relacionada con actividades lúdicas. Sus principales servicios son préstamo de todo tipo de materiales y talleres lúdicos que facilitan el entretenimiento, la formación académica y el fortalecimiento de valores y fomento a la lectura.

\section{Biblioteca Infantil "Miriam Álvarez Brenes"}

La Biblioteca Infantil "Miriam Álvarez Brenes" fue concebida por un grupo interdisciplinario e interunidades académicas de la Universidad Nacional, entre 1991-1993, inspirados en la idea de la bibliotecóloga Miriam Álvarez Brenes, quien propuso durante varios años la creación de una biblioteca infantil para Heredia. Esta biblioteca surge como un proyecto de extensión universitaria.

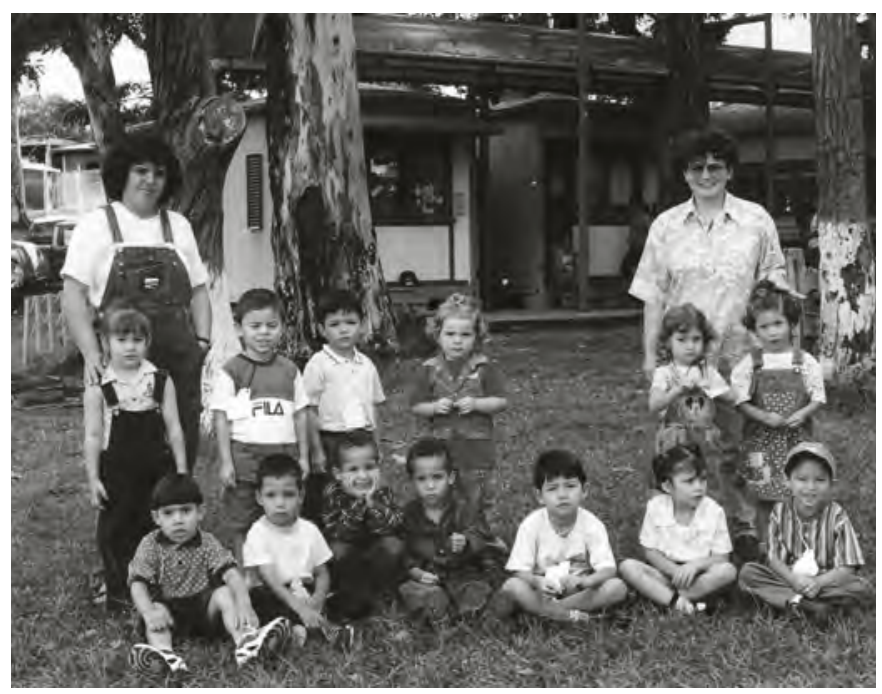

Con el apoyo de la Primera Dama de la República de esa época, Doña Gloria Bejarano, se logró la donación de un vagón de tren y dos contenedores para crear un espacio de viaje ficticio y motivar a los niños y a las niñas para desarrollar los encantos de la imaginación. 
En 1994 inicia oficialmente el proyecto, con el deseo de "ser un centro de conocimiento para el esparcimiento, la formación y educación extracurricular de los niños y las niñas que la visitan. Ofrecer actividades y experiencias de aprendizaje que estimulen en el niño y la niña sus capacidades; y habilidades, además de la incorporación constante de conocimiento nuevo mediante talleres dirigidos, lecturas y actividades audiovisuales".

Una de las fortalezas del proyecto es estar ubicado dentro de la Universidad Nacional y servir de puente de conocimiento entre la Universidad y las Comunidades Jardines Universitarios 1 y 2.

Esto les permite a los niños interactuar en un ambiente académico por excelencia y a los universitarios contribuir, desde diferentes perspectivas metodológicas y por áreas del conocimiento, al desarrollo integral de los niños y niñas.

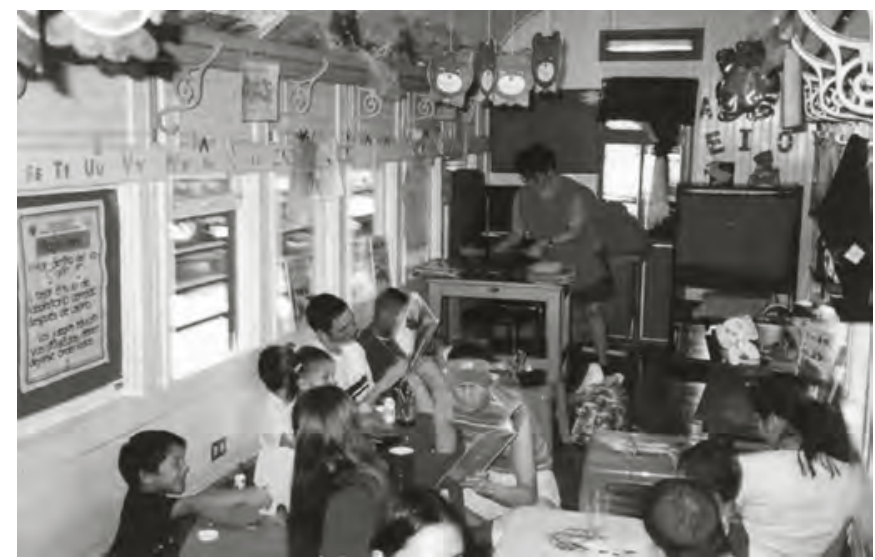

Las Comunidades Jardines Universitarios 1 y 2 son carenciales. Se encuentran desprovistas de espacios adecuados donde los niños y las niñas puedan esparcirse para satisfacer sus necesidades físicas e intelectuales. La Biblioteca Infantil "Miriam Álvarez Brenes" es el único espacio cultural dirigido a ellos en esas comunidades. Desde la biblioteca aprenden a compartir, a utilizar la tecnología, a socializar sus emociones, a arraigar valores, a concretar sueños y a imaginar un mundo mejor para todos. 
En ese mundo mágico de ensueño y de colores, el niño y la niña se ven atrapados en el disfrute del aprendizaje de otros idiomas, en el juego, las manualidades y el diálogo, en un ambiente carente de represión o correcciones que evidencien sus errores. Este tipo de actividades las realizan con el apoyo de estudiantes de niveles avanzados de la Escuela de Literatura y Ciencias del Lenguaje y de la Escuela de Arte Escénico, entre otras, con la colaboración en algunas ocasiones de la Vicerrectoría de Vida Estudiantil.

La Biblioteca Infantil "Miriam Álvarez Brenes" es un laboratorio para todas y cada una de las especialidades de la Universidad; en especial para las artes y la formación docente, donde los proyectos formulados que pretenden transformar situaciones o desarrollar un mejor mañana, pueden ser construidos, ejecutados y evaluados desde este pequeño mundo.

Las autoridades universitarias han sido visionarias y generosas al apoyar con este proyecto, dirigido a los niños y las niñas de una comunidad aledaña carencial, con el interés social costarricense que pretende separar a la población infantil de las calles y de los vicios. Es congruente con los principios de la universidad necesaria, que reza el Estatuto Orgánico, para lo cual debe realizar proyectos de extensión en beneficio de las comunidades más desposeídas.

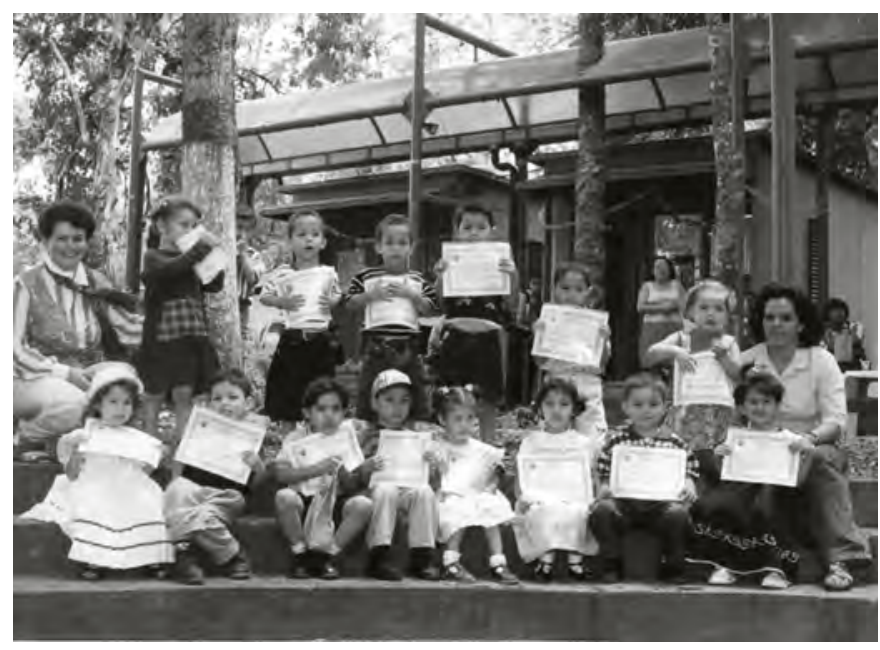


Cabe destacar que la Asociación Comunitaria Jardines Universitarios señala a la Biblioteca Infantil "Miriam Álvarez Brenes" como un logro para su comunidad, indicándolo de esa forma en los carteles que exhibe.

\section{BIBLIOTECAS UNIVERSITARIAS}

En Costa Rica, las universidades se organizan en dos grupos: universidades públicas estatales (4) y universidades privadas (cerca de 50).

Las universidades públicas están integradas por mandato nacional en el Consejo Nacional de Rectores que surge como una necesidad de integrar programas, proyectos y actividades educativas; así como para gestionar y compartir recursos a nivel nacional e internacional en forma cooperativa.

Las bibliotecas universitarias estatales cuentan con varias acciones cooperativas y ejecutan un plan de desarrollo en conjunto que enfatiza: desarrollo de colecciones electrónicas, actividades de actualización, pasantías, normalización de herramientas de almacenamiento y recuperación de la información, préstamo interbibliotecario, la integración de los catálogos en línea de los cuatro sistemas bibliotecarios mediante el software libre Dspace, lo cual se constituye en su meta inmediata, a fin de que los universitarios costarricenses puedan consultar cerca de un millón de títulos y solicitar en línea un préstamo interbibliotecario, si es necesario (Quirós, 2006, p. 15).

Estos sistemas bibliotecarios también integran la Red de Sistemas Integrados de Información Documental (Red-SIID) desde 1994, cuyo propósito es desarrollar un sistema de información documental de universidades centroamericanas, con una estructura orgánica consolidada.

\section{ENSEÑANZA BIBLIOTECOLÓGICA}

\section{Universidad de Costa Rica}

La enseñanza de la bibliotecología en Costa Rica fue impulsada desde la Biblioteca de la Universidad de Costa Rica y la Biblioteca Nacional, 
con cursos cortos, por el bibliotecólogo Alberto Bolaños y el escritor Julián Marchena. Posteriormente, se ofrecen cursos organizados por el Ministerio de Educación Pública y la Biblioteca de la Universidad de Costa Rica para bibliotecarios en servicio.

En el Área de Docencia, el primer Plan de Estudios de la Carrera de Bibliotecología, con el título de Bachillerato en Ciencias de la Educación, con especialidad en Bibliotecología, se inició en 1968 adscrito a la Rectoría. En 1969 pasa a formar parte de la Facultad de Educación.

En la actualidad, la Escuela de Bibliotecología y Ciencias de la Información ofrece los siguientes planes de estudio:

- Bachillerato en Bibliotecología con énfasis en Bibliotecas Educativas.

- Bachillerato y Licenciatura en Bibliotecología con énfasis en Ciencias de la Información.

- Licenciatura en Bibliotecología y Ciencias de la Información.

- Maestría en Bibliotecología y Estudios de la Información.

En el Área de investigación se tienen las siguientes líneas investigativas:

- Información y género

- Administración, gestión y liderazgo universitario

- Tecnologías de la comunicación y la información

- Educación y cultura

El Área de acción social se proyecta "hacia la comunidad del país que no ha logrado el ingreso formal a los estudios universitarios con el propósito de poner en contacto a los profesionales con la realidad y la problemática nacional" (Montero Gálvez, 2001, p. 81).

La organización estructural de la Escuela es la siguiente: 
Organigrama no. 2

Universidad de Costa Rica

Escuela de Bibliotecología y Ciencia de la Información

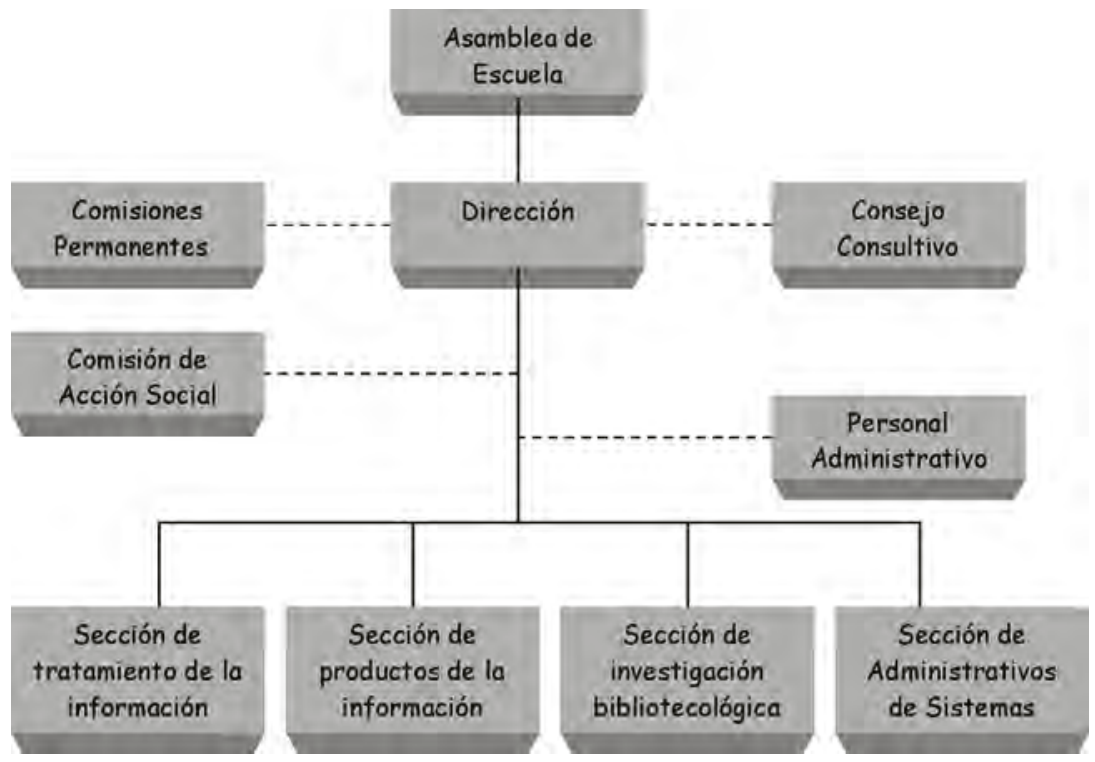

Fuente: Montero Gálvez, V., Díez Solano, L. Salas Sánchez, B. (2001) Visión histórica de la Carrera de Bibliotecología y Ciencias de la Información de la Universidad de Costa Rica de 1968 a 1998. San José,

C.R. : EUCR, p. 71.

\section{Universidad Nacional}

En la sesión extraordinaria no. 131, del 21 de octubre de 1976, el Consejo Directivo de la Facultad de Filosofía, Artes y Letras aprueba el Plan de Estudios de la Bibliotecología y Documentación y el Consejo Nacional de Rectores su ejecución a partir del 9 de marzo de 1977.

El fin primordial de la Escuela de Bibliotecología, Documentación e Información es formar profesionales frente a la Sociedad de la Información-Conocimiento con destrezas y habilidades que le permitan enfrentar la Bibliotecología moderna, inserta en el ciberespacio, desde una perspectiva local y autóctona.

El organigrama de la Escuela es el siguiente: 
Organigrama no. 3

Universidad Nacional (Costa Rica)

Escuela de Bibliotecología, Documentación e Información

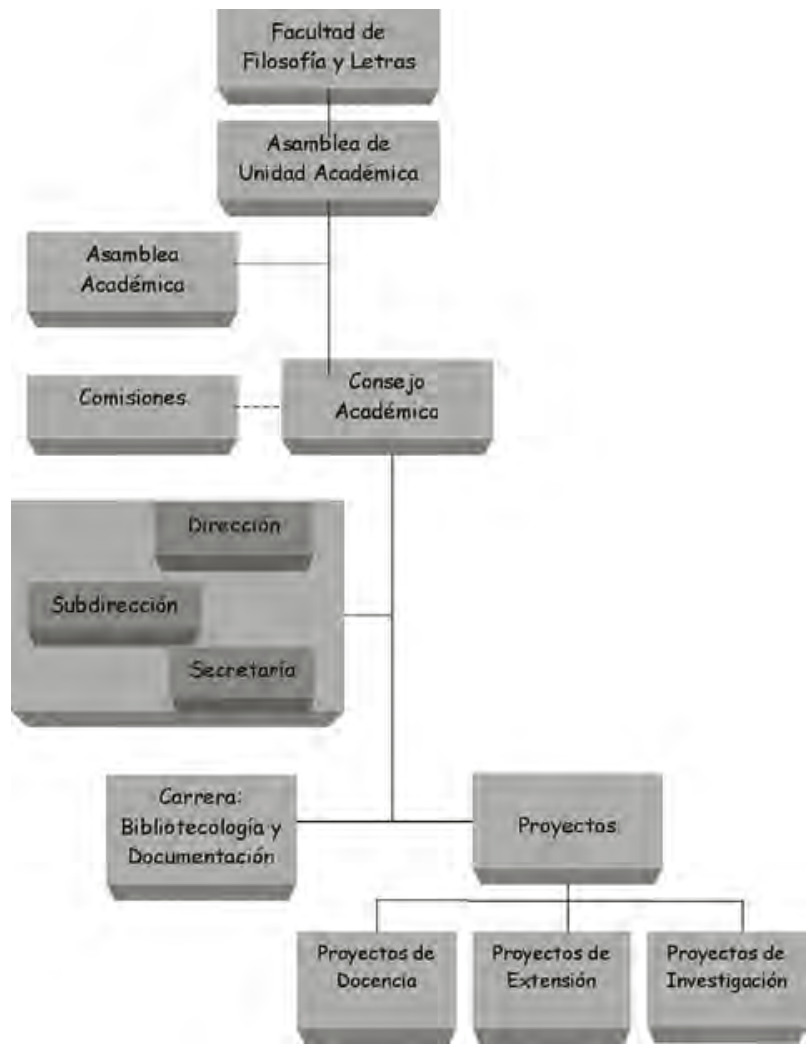

Fuente: Universidad Nacional (Costa Rica). Escuela de Bibliotecología, Documentación e Información (2005). Informe final Proceso de autoevaluación con miras a la acreditación. Heredia, C. R. : UNA, p. 58)

La oferta académica (planes de estudio y programas, proyectos y actividades) está conformada por cuatro áreas disciplinarias:

1. Área de Organización de Información Documental: relacionada con todos los procesos de almacenamiento y recuperación de la información. 
2. Área de Investigación: se cimienta en aspectos relativos a la epistemología, metodología e investigación bibliotecológica (teoría y cultura informacional).

3. Área Lectores/Usuarios/Clientes de la Información: comprende diseño de perfiles, capacitación, estudios de usuarios, inteligencia social, conocimiento organizacional sobre necesidades y consumo de información.

4. Área de Administración de Recursos y Servicios de Información: abarca aspectos relacionados con fundamentos, principios, normas, procesos e instrumentos para el desarrollo de colecciones, alcance, características, uso y evaluación de fuentes documentales; los servicios de acceso y disponibilidad de la información desde la perspectiva de extensión cultural universitaria y la prestación de servicios.

La construcción de un modelo integral de su oferta académica ha considerado tres ejes curriculares: herramientas de apoyo; la gestión organizacional; las tecnologías de la información y de la comunicación; y los métodos y técnicas de investigación y seis ejes transversales: elementos para la construcción del conocimiento con valores para el desarrollo social; género; equidad; desarrollo sostenible; diversidad cultural; ambiente y cultura ambiental (Universidad Nacional, Costa Rica, 2004, p. 8-11).

La Escuela ofrece en la dimensión de docencia los siguientes planes de estudio:

- Diplomado en Bibliotecología y Documentación.

- Bachillerato en Bibliotecología y Documentación con énfasis en Gestión de la Información.

- Bachillerato en Bibliotecología y Documentación con énfasis en Tecnologías de la Información y la Comunicación.

- Licenciatura en Bibliotecología y Documentación.

- Maestría en Cultura Centroamericana con mención en Gestión de la Información.

- Maestría en Cultura Centroamericana con mención en Bibliotecología y Documentación. 
La Escuela de Bibliotecología, Documentación e Información de la Universidad Nacional ha graduado 242 profesionales en los últimos cinco años.

Los proyectos de docencia inscritos en el 2006 son:

a. Unidad didáctica interactiva sobre procesamiento de información documental en formato electrónico, el cual cuenta con el apoyo económico de IFLA.

b. Aseguramiento de la calidad de la Carrera de Bibliotecología, Documentación e Información.

En el 2005 se logra la acreditación de la Carrera de Licenciatura y Bachillerato de Bibliotecología y Documentación, Sede Central del Sistema Nacional de Acreditación de la Educación Superior SINAES.

En la dimensión de investigación, la Escuela cuenta con los siguientes proyectos:

a. Centro de conocimiento para grupos étnicos indígenas centroamericanos.

b. Elaboración de una guía para elaborar unidades didácticas en Bibliotecología.

c. Perfil académico del profesional en Bibliotecología de una escuela acreditada.

d. Mapeo del control documental nacional y estudios métricos que caracterizan la identidad nacional e individual.

e. Alianzas estratégicas y convenios interinstitucionales como sinergias para el logro de una oferta académica novedosa, pertinente y moderna.

f. Diseño de un programa de educación continúa en Bibliotecología y Documentación.

g. Fundamentos teóricos y requerimientos profesionales que debe dominar el profesional en Bibliotecología y Documentación.

Además, los trabajos finales de graduación de los estudiantes contribuyen a la dimensión investigativa de la Escuela. 
En la dimensión de extensión cuenta con el proyecto Biblioteca Infantil "Miriam Álvarez Brenes", cuya misión está relacionada con aportar en una comunidad marginal los servicios y recursos de un centro de conocimientos enfatizando en talleres y dando seguimiento de su participación activa.

La práctica profesional supervisada le permite a los estudiantes participar en diferentes instituciones de carácter nacional e internacional, aportar a esta dimensión al interactuar estudiantes y jefes de unidades de información documental, lo cual es una fortaleza, porque surgen formas de pensamiento en torno a lo que han aprendido, lo que deberían saber y que sería importante conocer, convirtiéndose en un proceso de enriquecimiento mutuo entre la universidad y la sociedad.

La Escuela publica, ininterrumpidamente desde 1980, el Boletín Bibliotecas, para divulgar su quehacer, así como dar a conocer investigaciones y aportes interesantes de estudiantes y profesionales del área.

\section{REFLEXIONES FINALES}

Costa Rica, con una población aproximadamente de 4.5 millones de habitantes, cuenta con más de 500 bibliotecas educativas, 33 bibliotecas públicas oficiales y 25 semioficiales, cuatro sistemas de bibliotecas universitarias estatales y aproximadamente 50 bibliotecas universitarias privadas, siete bibliotecas infantiles municipales y una biblioteca infantil como proyecto académico. En cuanto a bibliotecas especializadas, el número es amplio y difícil de lograr, estando mejor identificadas las de las áreas de salud, desastres, economía y ciencias sociales.

Una fortaleza con que cuenta el país es la existencia de la carrera de Bibliotecología en tres universidades estatales y a partir del 2007 en una universidad privada, un Sistema Nacional de Bibliotecas Públicas, un Sistema Nacional de Bibliotecas Educativas, así como un Sistema Municipal de Bibliotecas Infantiles.

Otra fortaleza con que se cuenta es la Ley del Colegio de Bibliotecarios de Costa Rica que regula el ejercicio de la profesión y obliga a las instituciones con bibliotecas a contratar profesionales afiliados al Colegio. 
La acreditación de la carrera de Bibliotecología y Documentación de la Universidad Nacional constituye un gran logro para la Bibliotecología costarricense por cuanto adquiere un estatus de calidad en igualdad de condiciones a cualquier otra carrera acreditada en el país por el SINAES (Sistema Nacional de Acreditación de la Educación Superior).

Finalmente, a manera de recomendación se pueden señalar las siguientes necesidades:

a. Los planes de estudio de Bibliotecología cuentan con programas modernos y con acceso a las TIC(s) y los académicos son profesionales altamente calificados; sin embargo, sería importante alcanzar un consenso entre las escuelas en relación con el perfil profesional, áreas disciplinarias, ejes curriculares y ejes transversales, así como el aseguramiento de la calidad. Condiciones que podrían dar origen a unas jornadas nacionales de formación profesional.

b. Otro aspecto fundamental por lograr es el desarrollo de políticas nacionales de información que permitan mediante la introducción agresiva de los TIC(s) y las actividades cotidianas del bibliotecólogo, dirigir al país hacia la Sociedad de la Información-Conocimiento.

c. Es conveniente idear un primer encuentro sobre los manifiestos de IFLA/UNESCO para Bibliotecas Públicas, Bibliotecas Escolares e Internet, lo que brindaría nuevas perspectivas a ambos sistemas.

\section{BIBLIOGRAFÍA}

Arguedas, B. \& Madrigal, C. (1995). Modelo regional de servicios y actividades para la promoción de hábitos de lectura: salas infantiles en las públicas de la subregión de Alajuela. Tesis para optar por el grado de Licenciatura en Bibliotecología y Ciencias de la Información. San José, C.R. : UCR. 
Asociación Demográfica Costarricense. (2005). Población del censo 2000. Extraído el 24 de febrero de 2005. Disponible en; www.adc.go.cr

Centro Centroamericano de Población e Instituto Nacional de Estadística y Censos. (2002). Costa Rica: estimaciones y proyecciones de población 1970-2100 actualizados al año 2000 y evaluación del censo 2000 y otras fuentes de información: informe metodológico. Extraído el 24 de febrero 2005. Disponible en: www.ccp.ucr.ac.cr/

Costa Rica, Ministerio de Cultura, Juventud y Deportes (2005). Sistema Nacional de Bibliotecas Públicas. San José, C. R. : MCJD.

Córdoba, S. (1980). El Sistema de bibliotecas públicas de Costa Rica: diagnóstico general de su funcionamiento y sugerencias para su mejoramiento. Tesis para optar al título de Licenciada en Bibliotecología y Ciencias de la Información. Escuela de Administración Educativa, Sección de Bibliotecología, Universidad de Costa Rica. San José, C. R. : UCR.

Garmendia, L. (2005). La Biblioteca educativa en Centroamérica como instrumento de apoyo en la formación de hábitos de investigación en estudiantes de secundaria. Heredia, C.R. : UNA.

Miranda, A., Ugalde, A., Benavides, J., Rodríguez, K. (2005) Autoevaluación con miras a la acreditación de la Carrera de Bibliotecología y Documentación. Heredia, C.R. : UNA.

Montero Gálvez, V., Díez Solano, L., Salas Sánchez, B.(2001). Visión histórica de la Escuela de Bibliotecología y Ciencias de la Información en la Universidad de Costa Rica de 1968 a 1998. San José, C. R. : EUCR. 
Obregón, R. (1955). "Nuestras bibliotecas antes de 1890". En Boletín de la Asociación Costarricense de Bibliotecarios. Vol. 1, no. 2.

Quirós J., M (2006) "Bibliotecas universitarias ofrecerán catálogos integrados". En Campus Universidad Nacional, C.R.

Rodríguez, O. (2002). "La escolarización de la biblioteca pública en Costa Rica: un aporte a la discusión". En Bibliotecas: Boletín de la Escuela de Bibliotecología, Documentación e Información. Vol. 20, nos. 1-2.

Rodríguez, O. y Méndez, X. (2005) La escolarización de la Biblioteca Pública, con una propuesta para extender la cobertura de las bibliotecas públicas oficiales a la comunidad. Heredia, C.R. : UNA.

Sanz, P. (2003). La biblioteca pública latinoamericana. Bibliotecas en Iberoamérica. Extraído el 10 de marzo de 2006. Disponible en: www.absysnet.com.

Universidad Nacional, Costa Rica. Escuela de Bibliotecología, Documentación e Información (2004) Plan de estudios de Licenciatura y Bachillerato en Bibliotecología y Documentación con salida lateral de Diplomado. Heredia, C.R.: UNA. 



\title{
La Red Nacional de Bibliotecas Públicas de México
}

\author{
Filiberto Felipe Martínez Arellano \\ Centro Universitario de Investigaciones Bibliotecológicas/UNAM \\ Alejandra Martínez del Prado \\ Dirección General de Bibliotecas \\ Consejo Nacional de Cultura y de las Artes, México
}

\begin{abstract}
in duda alguna, la biblioteca pública es una institución impor- tante en toda sociedad ya que contribuye significativamente al desarrollo de sus individuos. Su función principal es la de servir como centro de información para proporcionar a sus usuarios todo tipo de datos y conocimientos, además de que sus servicios se prestan sobre la base de la igualdad del acceso para todos los individuos sin discriminación alguna.

En México, las bibliotecas públicas conforman una red denominada Red Nacional de Bibliotecas Públicas, la cual cuenta con una existencia de más de veinte años puesto que en agosto del presente año (2006) se conmemora su vigésimo tercer aniversario. La creación de la Red Nacional de Bibliotecas Públicas puede ser considerada como uno de los proyectos más importantes de nuestro país en materia de bibliotecas. A lo largo de su existencia, la Red Nacional de Bibliotecas Públicas ha sido objeto de diversos esfuerzos para lograr su consolidación y ésta ha crecido significativamente. Hasta enero del presente año (2006), la Red Nacional de Bibliotecas Públicas estaba integrada por 6900 bibliotecas y para fines de éste año se preveía contar con 7200 bibliotecas públicas.
\end{abstract}




\section{ORIGEN Y DESARROLLO}

El origen de la Red Nacional de Bibliotecas Públicas se remonta al sexenio del Presidente Miguel de la Madrid, durante el cual fue presentado el Plan Nacional de Desarrollo 1983-1988, teniendo como objetivo principal impulsar una sociedad más igualitaria. Dicho plan estableció que "una sociedad más igualitaria requería, en el terreno educativo y cultural, de mecanismos que permitieran brindar a los mexicanos mayores oportunidades de acceso gratuito a la lectura a través de servicios bibliotecarios suficientes y adecuados en toda la República" (México. Secretaría de Educación Pública, 1988).

A la Secretaría de Educación Pública (SEP) le fue encomendada la tarea de elaborar y poner en marcha un programa para proporcionar a la población mayores posibilidades de acceso a las fuentes de información y conocimiento escrito. De esta forma, el 2 de agosto de 1983 fue establecido el Programa Nacional de Bibliotecas Públicas. En ese periodo, México presentaba una gran carencia de servicios bibliotecarios de carácter público, pues sólo existían 351 bibliotecas y éstas se encontraban en las principales ciudades del país. Ante esta situación, el Programa Nacional de Bibliotecas Públicas se planteó como objetivo el establecimiento de servicios bibliotecarios públicos y gratuitos en cada uno de los municipios del país.

Durante sus más de veinte años de existencia, el crecimiento de la Red Nacional de Bibliotecas Públicas ha sido significativo como puede ser observado en la siguiente gráfica.

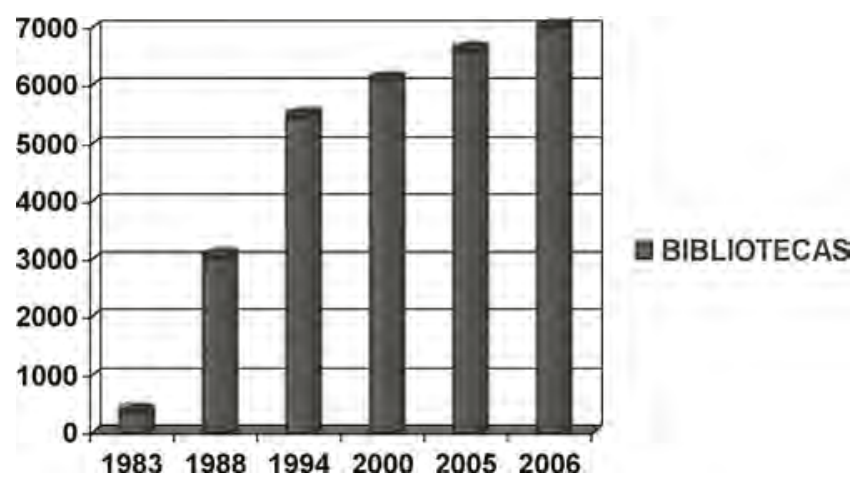


La Red Nacional de Bibliotecas Públicas ha pasado por cuatro etapas, cada una de las cuales presenta la marca particular de los sexenios correspondientes a las sucesivas administraciones federales (Von Ziegler, 2004):

- La primera etapa puede ser considerada como la fundación y expansión de la Red Nacional de Bibliotecas Públicas (1983-1988), en la cual la cantidad de bibliotecas públicas llegó a 3, 047.

- La segunda etapa se considera como un segundo periodo de expansión (1989-1994), pues durante este sexenio surgió la necesidad de asegurar la permanencia de las bibliotecas públicas, por lo que los esfuerzos se concentraron en el fortalecimiento de la Red Nacional y la cantidad de bibliotecas se incrementó a 5, 470.

- La tercera etapa corresponde a un periodo de consolidación (1995-2000). En estas fechas se incorporan servicios adicionales tales como: mapoteca, hemeroteca y diversos talleres en las bibliotecas públicas de algunas ciudades importantes. Para el año 2000 existían 6, 101 bibliotecas públicas en operación.

- La cuarta y última etapa se define como un periodo de consolidación y modernización (2001-2006). Uno de los objetivos de este sexenio ha sido extender y mejorar sustancialmente la calidad del servicio de la biblioteca pública. Para el año 2003 existían 6, 410 bibliotecas. La meta del presente sexenio es contar con 7, 200 bibliotecas para finales del año 2006.

El incremento cuantitativo no es el único elemento que demuestra el desarrollo de las bibliotecas públicas en México, pues no se puede dejar fuera la parte cualitativa, la cual también muestra que se han tenido avances en materia de bibliotecas públicas. Desde sus inicios, la existencia de la Red Nacional de Bibliotecas Públicas ha coadyuvado a cambiar la visión sobre las bibliotecas públicas de nuestro país. Al respecto, Magaloni (citada por Fernández de Zamora, 2003) señala lo siguiente:

"En muchas partes, la biblioteca se convirtió en un centro de convivencia de la comunidad, con ciclos de lectura, exposiciones, conferencias, cursos de verano y otras actividades de difusión y extensión". 


\section{ESTRUCTURA Y ORGANIZACIÓN}

La Red Nacional de Bibliotecas Públicas no podía desarrollarse satisfactoriamente bajo un esquema centralista de trabajo, sino que fue necesaria la colaboración de los distintos niveles de gobierno. Por lo tanto, su establecimiento y operación se planteó bajo un esquema fundado en la colaboración y en la distribución de responsabilidades entre la Federación, los Estados y los Municipios del país.

La Red Nacional de Bibliotecas Públicas se constituyó con todas aquellas bibliotecas públicas dependientes de la Secretaría de Educación Pública que estaban en operación al iniciarse este programa y con aquellas creadas posteriormente conforme a los acuerdos o convenios de colaboración y coordinación celebrados entre la propia Secretaría y los gobiernos estatales y el del Distrito Federal.

Actualmente, la Red Nacional de Bibliotecas Públicas es coordinada por la Dirección General de Bibliotecas del Consejo Nacional para la Cultura y las Artes (CONACULTA) y se encuentra conformada -en virtud de los referidos acuerdos de colaboración y coordinaciónpor 31 redes estatales y por 16 redes delegacionales del Distrito Federal, cada una de ellas integrada por todas las bibliotecas públicas establecidas en la entidad o en la delegación política respectiva. Estas redes estatales o delegacionales son coordinadas por las coordinaciones estatales o delegacionales, las cuales funcionan como vínculo entre la Dirección General de Bibliotecas del CONACULTA y la red de bibliotecas de cada estado o delegación.

Las redes estatales están conformadas por: una Biblioteca Pública Central Estatal, la cual se caracteriza por ser la más grande del estado, y que además de coordinar a las bibliotecas de un estado, funge como biblioteca modelo; Bibliotecas Públicas Regionales, las cuales cumplen la función de apoyo a las coordinaciones estatales; y Bibliotecas Públicas Municipales, las cuales conforman la gran mayoría de las bibliotecas públicas de nuestro país, ubicadas en las cabeceras municipales.

En resumen, las bibliotecas de la Red Nacional de Bibliotecas Públicas operan bajo un esquema de participación de los gobiernos $\mathrm{Fe}$ deral, Estatal y Municipal. La Red se constituye como un programa 
descentralizado fundado en la colaboración y en la distribución de responsabilidades de los tres niveles de gobierno. El Gobierno Federal está representado por la Dirección General de Bibliotecas del CONACULTA, quién actúa como el núcleo básico que coordina técnicamente la Red. El Gobierno Estatal está representado por cada Coordinación Estatal de Bibliotecas, que funciona como el órgano coordinador de la Red Estatal, establecido por el gobierno de cada entidad para que supervise la operación de las bibliotecas públicas. El Gobierno Municipal está representado por las bibliotecas públicas municipales.

\section{LA DIRECCIÓN GENERAL DE BIBLIOTECAS DEL CONACULTA}

La Dirección General de Bibliotecas (DGB) del CONACULTA tiene como misión coordinar técnica y normativamente el funcionamiento de la Red Nacional de Bibliotecas Públicas, formando y distribuyendo acervos bibliográficos, fomentando la lectura, capacitando al personal de las bibliotecas y promoviendo el desarrollo de la infraestructura bibliotecaria, para contribuir a la equidad en el acceso libre e ilimitado de todas las personas al conocimiento, el pensamiento, el arte, la cultura y la información. Asimismo, su visión es constituir un moderno centro nacional regulador y de servicios para las bibliotecas públicas del país, con sistemas actualizados y herramientas avanzadas para procurar directrices de funcionamiento, asistencia técnica y profesional, acceso a colecciones de documentos, gestión automatizada, desarrollo informático y de telecomunicaciones y pautas de animación encaminadas a la información de usuarios y lectores.

Para lograr lo anterior, la Dirección General de Bibliotecas del CONACULTA, actualmente se encuentra conformada por cinco Direcciones: 


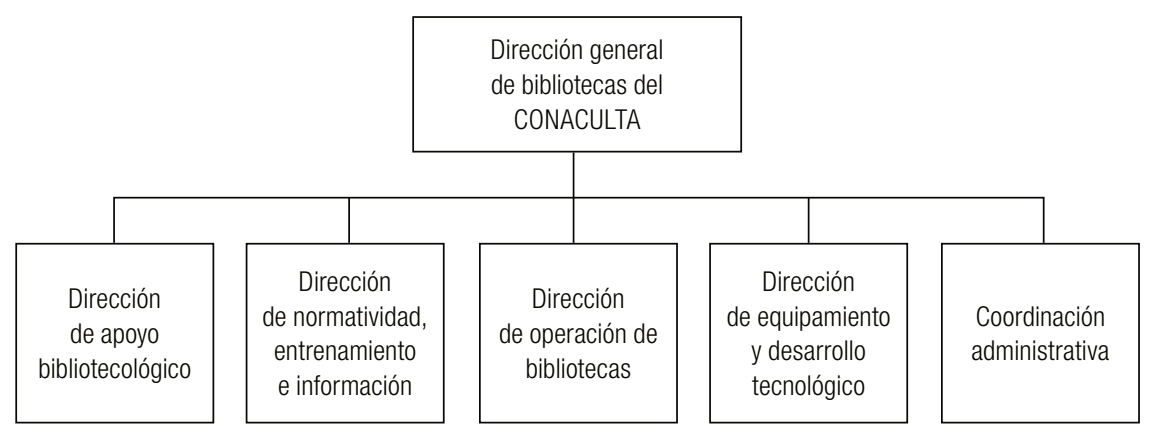

Como parte del Programa Nacional de Cultura 2001-2006 en materia de bibliotecas públicas, la Dirección General de Bibliotecas del CONACULTA ha tenido como campos de acción fundamentales el mejoramiento de las instalaciones de las bibliotecas públicas ya existentes; la creación de nuevas bibliotecas; la ampliación de los programas de capacitación del personal; y la introducción de nuevas fuentes de información, capaces de aumentar la disponibilidad de libros, materiales de lectura, documentos e información de todo tipo en la biblioteca. En relación con éste último campo, se ha incluido la construcción de un nuevo edificio para la Biblioteca de México (Von Ziegler, 2004a).

\section{CAPACITACIÓN DEL PERSONAL}

Uno de de los principales problemas que enfrentan las bibliotecas públicas en México es la carencia de personal con una formación adecuada para desarrollar las actividades y prestar los servicios bibliotecarios. Uno de los factores que influyen en esta situación es la frecuente movilidad del personal de quienes laboran en este tipo de bibliotecas, así como el monto de los salarios, el cual no es competitivo con el de otro tipo de bibliotecas.

Los aspectos mencionados anteriormente tienen repercusión en los servicios que se brindan por lo que ante esta situación, la Dirección General de Bibliotecas del CONACULTA ha establecido dentro de sus acciones prioritarias la capacitación del personal bibliotecario, la 
cual está bajo la responsabilidad de la Dirección de Normatividad, Entrenamiento e Información. En ésta se ha elaborado un programa de capacitación técnica básica para el personal bibliotecario, en el cual se considera el perfil que deberán tener los bibliotecarios, así como cubrir las necesidades para brindar servicios adecuados.

La capacitación bibliotecaria se ofrece a través de diversos talleres de entrenamiento, los cuales brindan a los bibliotecarios en servicio una serie de conocimientos básicos, con el objetivo de que logren modificar sus actitudes y desarrollar ciertas habilidades para que puedan desempeñar de forma adecuada su trabajo. Los talleres de entrenamiento que actualmente brinda la Dirección General de Bibliotecas son: Entrenamiento básico; Estrategias de promoción y mercadotecnia en beneficio de la biblioteca pública; Introducción al desarrollo de habilidades informativas; La reparación de los libros; La organización de los catálogos; Taller para coordinadores; Formación de instructores; y Taller de servicio de información local a la comunidad en la biblioteca pública. Estos talleres son impartidos por un grupo de instructores, los cuales viajan durante todo el año a los diferentes estados del país. Para la impartición de estos talleres se apoyan en diversos documentos y materiales didácticos, tales como las Directrices IFLA/UNESCO para el desarrollo del servicio de bibliotecas públicas, así como instructivos, manuales, folletos y cuadernos de trabajo editados por la Dirección General de Bibliotecas del CONACULTA.

\section{Programas Y LÍNEAS DE ACCIÓN RELEVANTES}

Uno de los proyectos más relevantes de la Red Nacional de Bibliotecas Públicas ha sido el Programa Nacional "Hacia un País de Lectores", el cual fue puesto en marcha en el año 2001 por el Presidente de México, Vicente Fox. Este programa ha sido definido como "el conjunto de esfuerzos que el gobierno de la República propone a la sociedad para incorporar la lectura en la vida de todos los mexicanos: en el hogar, escuela, universidad, espacios culturales, lugares públicos y centros de distribución y acceso a los libros y a otros materiales de lectura". (Consejo Nacional para la Cultura y las Artes (2001a)). 
Otra de las acciones que es importante mencionar es el auspicio de la Campaña "Por las Bibliotecas Mexicanas", la cual forma parte de la campaña mundial "Por las Bibliotecas del Mundo", promovida por la IFLA, a la que México se unió en el año 2002. Las bibliotecas que forman parte de la Red Nacional de Bibliotecas Públicas realizan acciones para promover su importancia y el papel que estas juegan en la sociedad.

Por otra parte, cabe destacar la celebración de encuentros y congresos para discutir la problemática de las bibliotecas públicas mexicanas. A lo largo del sexenio, 2001-2006, se han realizado tres Encuentros Internacionales sobre Bibliotecas Públicas. El primero tuvo lugar en la Ciudad de México del 24 al 28 de septiembre de 2001, el segundo se realizó en Puerto Vallarta, Jalisco del 21 al 23 de agosto de 2003 y el tercero se llevó a cabo en la Ciudad de México el 18 y 19 de noviembre de 2005, en el marco de la XXV Feria Internacional del Libro Infantil y Juvenil. Asimismo, a partir del año 2001 se han realizado cinco Congresos Nacionales de Bibliotecas Públicas en diferentes estados del país, siendo éstos: Coahuila, Jalisco, Durango, Estado de México y San Luís Potosí. Tanto los encuentros internacionales como los congresos nacionales han contado con la presencia de destacados profesionales de la Bibliotecología, tanto nacionales como de otros países. Los programas de éstos han incluido una serie de conferencias, así como diversos talleres y cursos. Estos eventos han permitido el intercambio de ideas y experiencias para fomentar un mejor desarrollo de las bibliotecas públicas de nuestro país. Cabe señalar que como producto de los diferentes encuentros y congresos realizados se han publicado las memorias correspondientes, las cuales son distribuidas de manera gratuita a todas las bibliotecas de las diversas entidades federativas del país.

La Dirección General de Bibliotecas del CONACULTA también se ha dado a la tarea de elaborar una publicación mensual denominada El bibliotecario. Esta publicación tiene como finalidad la difusión de las diversas actividades que lleva a cabo la Dirección General y las bibliotecas públicas de la Red Nacional. En sus inicios, esta publicación era un boletín informativo pero ahora tiene la calidad de revista. Esta revista es distribuida de manera gratuita no sólo a las bibliotecas públicas de la Red Nacional, sino también se hace llegar a otras instituciones académicas. Esta 
publicación también se encuentra disponible en línea para ser consultada desde cualquier lugar del mundo.

Con relación a las estrategias de equipamiento tecnológico, es importante señalar que la Dirección General de Bibliotecas, a través de su Dirección de Equipamiento y Desarrollo Tecnológico, puso en marcha el Programa de Acceso a Servicios Digitales en Bibliotecas Públicas con el objetivo de apoyar el fortalecimiento y la modernización de las bibliotecas de la Red Nacional para ofrecer servicios digitales públicos y gratuitos, principalmente en comunidades marginadas. El programa estableció como meta ofrecer para el año 2006 acceso a Internet a tres millones de personas, para lo cual se conformó un grupo asesor integrado por representantes de diversas instituciones, quienes analizaron y propusieron la distribución de un donativo otorgado por la Fundación Bill y Melinda Gates y la e mpresa Microsoft México. Como parte de este programa se seleccionaron 675 bibliotecas y el ocho de enero del año 2004 fueron instalados los primeros Módulos de Servicios Digitales en Bibliotecas Públicas. El estado que tuvo el mayor número de bibliotecas públicas beneficiadas por dicho programa fue Oaxaca.

Asimismo, la Dirección General de Bibliotecas ha impulsado y organizado un programa anual para el fomento a la lectura, principalmente entre los niños, denominado Mis vacaciones en la biblioteca. Este programa ha demostrado tener gran aceptación por parte de los pequeños usuarios de las bibliotecas públicas de la Red Nacional, pues a través de juegos y diversión, los niños son invitados a adquirir el hábito por la lectura, además de que toman conciencia sobre la biblioteca pública como un centro de información, el cual resulta un complemento para sus actividades escolares así como para su formación y desarrollo personal.

La construcción del nuevo edificio de la Biblioteca de México, la biblioteca pública más grande de la Ciudad de México, es otro de los proyectos de la presente administración. Este constituye una acción de particular relevancia para el mejoramiento, ampliación y modernización de la infraestructura de la Red Nacional de Bibliotecas Públicas, pues a través de éste se espera propiciar la consolidación y el reconocimiento entre la población de los diversos servicios que ofrece una 
biblioteca pública. Esta biblioteca también será la cabeza de la Red Nacional de Bibliotecas Públicas y además servirá como modelo para determinar los procedimientos, lineamientos y servicios que una institución de esta índole debe brindar a la comunidad.

La nueva sede de la Biblioteca de México tendrá una función estratégica en la creación y la operación de una red tecnológica en las bibliotecas públicas. El nuevo edificio está concebido como el centro de servicios a distancia para las bibliotecas estatales, regionales y municipales de toda la Red Nacional. Albergará el centro de soporte técnico que brindará atención a los módulos de Internet instalados en las bibliotecas públicas, mediante orientación a los responsables de su operación en el uso, la resolución de fallas y problemas, el mantenimiento y la comunicación. También se encargará del monitoreo y evaluación de los módulos de Internet en toda la Red y será un espacio para poder realizar la capacitación presencial y a distancia del personal bibliotecario en el uso de las tecnologías de información y comunicación. (Von Ziegler, 2003). Se espera que para el mes de abril del presente año el nuevo edificio de la Biblioteca de México, denominada Biblioteca José Vasconcelos, se encuentre en funcionamiento y esté abierto para todo el público.

\section{CONSIDERACIONES FINALES}

A pesar de las dificultades y obstáculos por los que ha atravesado nuestro país, la Red Nacional de Bibliotecas Públicas ha logrado mantenerse viva por más de veinte años. No cabe duda que en los últimos años se han llevado a cabo esfuerzos para alcanzar sus objetivos, logrando así la integración y actualización de las bibliotecas que conforman la Red Nacional de Bibliotecas Públicas, lo cual no es tarea fácil. Ciertamente, la situación actual de las bibliotecas públicas en México no es la óptima y la que muchos pudiésemos desear; sin embargo, ésta es totalmente diferente a la existente hace veinte años. Ante esta situación, aún queda mucho trabajo por hacer por lo que los bibliotecarios tenemos que redoblar esfuerzos para seguir apoyando a este tipo de biblioteca, pues es una de las instituciones públicas que más inciden 
para alcanzar un mejor desarrollo económico, social y cultural de las naciones.

\section{REFERENCIAS Y OBRAS CONSULTADAS}

Cabrera Bohórquez, Jorge. (2003). La UNESCO: marco de referencia de la Red Nacional de Bibliotecas Públicas. En Memoria del Tercer Congreso Nacional de Bibliotecas Públicas "A 20 años de la Red Nacional" realizado en Durango, Durango del 25 al 27 de septiembre de 2003 (p. 52-59). México: CONACUlTa. Dirección General de Bibliotecas.

Consejo Nacional para la Cultura y las Artes. (1991). La Red Nacional de Bibliotecas. México: CONACULTA. Dirección General de Bibliotecas.

Consejo Nacional para la Cultura y las Artes. (1997). Ley General de Bibliotecas México: CONACUlTA. Dirección General de Bibliotecas. También disponible en: http://www.cnb.org.mx/leygeneralbiblio.pdf

Consejo Nacional para la Cultura y las Artes. (2001). Programa Nacional de Cultura 2001-2006. México: Consejo Nacional para la Cultura y las Artes.

Consejo Nacional para la Cultura y las Artes. (2001a). Programa Nacional Hacia un País de Lectores. México: Consejo Nacional para la Cultura y las Artes.

Escalona Ríos, Lina. (2003). Bibliotecas y sociedad: un reto para el nuevo siglo. En Memoria del Primer Congreso Nacional de Bibliotecas Públicas y Centros Documentales "Futuro y perspectivas de los servicios bibliotecarios $y$ de información" realizado en Saltillo, Coahuila, del 11 al 13 de Junio de 2001 (p. 105-116). México: CONACULTA. Dirección General de Bibliotecas. 
Federación Internacional de Asociaciones de Bibliotecarios e Instituciones. (1994). Manifiesto IFLA/UNESCO sobre la biblioteca pública. Disponible en:

http://www.ifla.org/VII/s8/unesco/span.htm

Federación Internacional de Asociaciones de Bibliotecarios e Instituciones. (2002). Directrices IFLA/UNESCO para el desarrollo del servicio de bibliotecas públicas. México: CONACULTA. Dirección General de Bibliotecas; IFLA.

Fernández de Zamora, Rosa María. (2001). Las bibliotecas públicas en México: historia, concepto y realidad. En $M e$ moria del Primer Encuentro Internacional sobre Bibliotecas Públicas "Perspectivas en México para el silgo $X X I$ " realizado en la Cuidad de México del 24 al 28 de septiembre de 2001 (p. 13-32). México: CONACUlTa. Dirección General de Bibliotecas.

Fernández de Zamora, Rosa María. (2003). La Red Nacional de Bibliotecas Públicas en su vigésimo aniversario. En El Bibliotecario, Año 3, No. 26, p. 11-16.

Lizalde, Eduardo. (2003). Las bibliotecas públicas: realidad y futuro. En Memoria del Primer Congreso Nacional de Bibliotecas Públicas y Centros Documentales "Futuro $y$ perspectivas de los servicios bibliotecarios y de información" realizado en Saltillo, Coahuila, del 11 al 13 de Junio de 2001 (p. 119-132). México: CONACUlTA. Dirección General de Bibliotecas.

México. Secretaría de Educación Pública. (1988). Programa Nacional de Bibliotecas Públicas 1983-1988 y el Centro Bibliotecario Nacional Biblioteca Pública de México. México: Secretaría de Educación Pública. Dirección General de Bibliotecas. 
Ríos Ortega, Jaime. (2003). La biblioteca pública: un lugar de valores. En Memoria del Segundo Encuentro Internacional sobre Bibliotecas Públicas "Modelos de Biblioteca Pública en Iberoamérica" realizado en Puerto Vallarta, Jalisco, México, del 21 al 23 de agosto de 2003 (p. 311-322). México: ConaCulTa. Dirección General de Bibliotecas.

Von Ziegler, Jorge. (2003). La Biblioteca de México, un proyecto para la sociedad de la información. En Memoria del Segundo Encuentro Internacional sobre Bibliotecas Públicas "Modelos de Biblioteca Pública en Iberoamérica" realizado en Puerto Vallarta, Jalisco, México, del 21 al 23 de agosto de 2003 (p. 233-239). México: CONACUlTA. Dirección General de Bibliotecas.

Von Ziegler, Jorge. (2004). Futuro de las redes de bibliotecas públicas. En El Bibliotecario, Año 4, No. 37, p. 21-25. (Ponencia presentada en las XXXV Jornadas Mexicanas de Biblioteconomía, realizadas en Cancún, Quintana Roo del 11 al 14 de mayo de 2004).

Von Ziegler, Jorge. (2004a). La Red Nacional de Bibliotecas Públicas: proyectos 2001-2006. En Memoria del Cuarto Congreso Nacional de Bibliotecas Públicas "Avances del Programa Nacional de Cultura en el área de Bibliotecas Públicas" realizado en Toluca, Estado de México, del 23 al 25 de septiembre de 2004 (p. 45-51). México: CONACULTA. Dirección General de Bibliotecas. 



\title{
La lectura en la Región de América Latina y el Caribe
}

\author{
ELSA M. RAMÍREZ LEYVA \\ Centro Universitario de Investigaciones Bibliotecológicas /UNAM
}

\section{ANTECEDENTES}

lo largo del siglo Xx tuvo lugar una expansión de las posibilida$A$ des de acceso a los libros y la lectura, principalmente median- Le las bibliotecas públicas, las populares y otras modalidades coordinadas por diferentes instituciones y organismos, como parte de los proyectos para lograr pueblos educados; en función de todo ello se establecieron jerarquizaciones, caracterizaciones o tipologías de públicos lectores. A la par fue conformándose un discurso de la lectura sobre la base de su utilidad para retener, reproducir contenidos, modelar conductas y actitudes; se pensó que la lectura lúdica, recreativa y asidua sería una consecuencia del paso por la institución escolar. Por otra parte, el utilitarismo que imperó en el proceso educativo concordaba con los modelos políticos y económicos dirigidos a alcanzar el progreso. En función de todo ello se establecieron jerarquizaciones o tipologías de públicos lectores y la modelación de las prácticas de lectura. Sin embargo, en porciones significativas de la población, persisten condiciones de pobreza y marginación, aunadas a la desigualdad para acceder a la cultura escrita, lo que agrava la exclusión histórica de algunos sectores sociales de nuestra región, al 
limitarles el beneficio que puede aportarles la lectura, la información y la literatura.

Hoy, en la medida en que prospera el tránsito hacia la Sociedad de la Información, surge de nuevo una clara intención de dirigir esfuerzos a formar una sociedad lectora, capaz de hacer un uso eficiente de la información, con destrezas superiores a las expectivas de la Pedagogía y la Bibliotecología del siglo XX.

El tema de la lectura en los países de América Latina y el Caribe no ha dejado de ser considerado como uno de los problemas prioritarios; en el presente adquiere relieve pues en el concierto mundial, nuestra región aparece en desventaja por las deficiencias en las destrezas de lectura y escritura, en especial entre los jóvenes que concluyeron nueve años de escolaridad, por las tasas de analfabetismo, por el nivel educativo de los ciudadanos, por la disparidad en el acceso al libro y la lectura, entre otros factores. Estos son obstáculos para acceder a las diferentes posibilidades de las diversas alternativas de información, asi como a la educación para toda la vida. Lo anterior lo podemos encontrar en los siguientes datos:

\begin{tabular}{|c|l|}
\hline Analfabetismo & $\begin{array}{l}11 \% \text { (36 millones) de la población de América Latina declara no saber leer ni } \\
\text { escribir. } \\
\text { En } 11 \text { de } 24 \text { países, su población de } 15 \text { años y más registran una tasa de } \\
\text { analfabetismo de 10-20\%; considerando hombres y mujeres, ellas en mayor } \\
\text { porcentaje. }{ }^{1}\end{array}$ \\
\hline \multirow{2}{*}{ Nivel de educación } & $\begin{array}{l}25 \% \text { de jóvenes no concluyen la educación básica. (No logran los seis años } \\
\text { de educación básica). } \\
64 \% \text { de niños no concluyen la educación básica en cuatro países de } \\
\text { Centroamérica. } \\
40 \% \text { de la población latinoamericana no llega al nivel de secundaria (tres años } \\
\text { posteriores a la educación básica de seis años). }\end{array}$ \\
\hline Número de bibliotecas & $\begin{array}{l}14,616 \text { bibliotecas públicas para una población de } 551,764,000 \\
\text { habitantes. } \\
\text { Eúblicas en América Latina de escuelas a nivel básico con bibliotecas no llega al 1\%, por lo } \\
\text { tanto, las bibliotecas públicas cubren las funciones de las escolares. }\end{array}$ \\
\hline
\end{tabular}

1 Los datos sobre analfabetismo y educación están basados en la información que proporcionan las Naciones Unidas. 


\section{LA LECTURA EN AMÉRICA LATINA Y EL CARIBE}

Entre los problemas relacionados con la lectura, que son comunes en los países de América Latina y el Caribe, tenemos los siguientes:

- Falta de estudios que aporten, de manera confiable, el estado real que guarda la lectura en nuestra región.

- Prevalece la lectura precaria en cantidad y calidad. Lectura de materiales que no contribuyen al enriquecimiento del capital lingüístico ni cultural.

- Problemas de comprensión de contenidos.

- Inadecuada incorporación de la práctica de la lectura por gusto.

- Desigualdad en las competencias y en la distribución de las posibilidades para acceder a los libros y a la lectura.

- Bibliotecas públicas y bibliotecarios con limitaciones para emprender acciones correctivas a la lectura por obligación y a la lectura precaria.

- Promoción de la lectura dirigida principalmente a niños.

- Programas de fomento a la lectura que no son sostenidos (interrupciones, falta de apoyo, cambios de orientación).

- Comunidades rurales e indígenas con poblaciones orales, con diferentes lenguas, donde en algunos casos no hablan español o éste es muy precario y escasos servicios y recursos bibliotecarios.

- Necesidad de mayor participación de bibliotecarios capacitados para diseñar o innovar actividades de fomento a la lectura de mayor alcance.

- Recursos bibliográficos insuficientes.

- Desigualdad de distribución en el equipamiento para el acceso a Internet.

- Escasa actividad de fomento a la lectura extramuros.

Ante estas problemáticas se han realizado reuniones regionales con el fin de solucionar los diferentes problemas mencionados, dada la importancia de la lectura como instrumento real para la inclusión social y un factor básico para el desarrollo social, cultural y económico de nuestros países. La lectura es una actividad que debe asumirse 
de manera consciente y manifestarse en las prácticas sociales. Ademas, se debe buscar la articulación de la lectura con la estructura cultural e involucrar a todos los sectores sociales mediante un plan sostenido a largo plazo, asi como revisar las políticas de lectura implícitas y explícitas a fin de autodirigirlas y adecuarlas a la realidad actual.

Al respecto, recientemente se han efectuado reuniones regionales: la XIII Cumbre Iberoamericana en 2003, en donde los jefes de estado reunidos emitieron una declaración y la Primera Reunión para la Formulación de una Agenda de Políticas de Lectura en 2004, en la que participaron los responsables de 21 países de los planes nacionales de lectura, convocada por CERLALC (Centro Regional para el Fomento del Libro en América Latina y el Caribe) y la Organización de Estados Iberoamericanos en el Plan Iberoamericano de Lectura ILÍMI$\mathrm{TA}^{2}$ (Programa Cumbre de Jefes de Estado y de Gobierno de Iberoamérica). En éste se adquirió el compromiso de articular a gobiernos, sectores privados y sociedad civil para que Iberoamérica emprenda o continúe acciones inmediatas y con proyección a largo plazo, a favor de la lectura; una de las recomendaciones fue la de impulsar investigaciones dirigidas a conocer la situación de la lectura en la región.

\section{EL PAPEL DE CERLALC}

Por otro lado, se encuentra el compromiso que tiene CERLALC con la Región Iberoamericana, el cual sirve como plataforma de integración en torno al desarrollo de políticas orientadas a la consolidación de sociedades

2 ILÍMITA es una plataforma de integración cultural de las naciones iberoamericanas, fundamentada en la lectura y la escritura como herramientas de inclusión social y desarrollo. Pretende dar a conocer todas aquellas iniciativas que trabajan por la lectura en Iberoamérica. ILíMITA trabaja para que la lectura se convierta en un tema prioritario en las políticas públicas y en el imaginario social de Iberoamérica. Divulga iniciativas gubernamentales, privadas y del tercer sector que trabajen por la lectura y la consideren un tema fundamental para el desarrollo. Además, realizan estudios y sistematizan datos entregados por los actores que dinamizan el tema en los países, que brinde insumos a todos a quienes adelantan o inician nuevas tareas locales o regionales a favor de la lectura. 
lectoras. De acuerdo con su programa técnico del año 2006, CERLALC tiene el compromiso de dar especial relevancia a la producción de estudios e investigaciones. Estas comprenden desde la consolidación de información estadística sobre el sector editorial y la circulación del libro entre los países de la región hasta el diseño de una metodología que permita medir el comportamiento lector, aplicable local y regionalmente, así como la construcción de indicadores cualitativos que permitan dar cuenta del aporte de la lectura al desarrollo social.

También ha orientado sus esfuerzos hacia la incorporación de la lectura en las agendas de política pública de los países; este objetivo se ha buscado de manera conjunta con el Plan Iberoamericano de Lectura ILÍMITA. Durante este año (2006) se propone fortalecer la dinámica de integración y de intercambio entre los responsables de las políticas en los países realizando las siguientes actividades: promover la conformación de la Red Regional de Responsables de Políticas de Lectura y hacer un seguimiento a los procesos de formulación de políticas y planes de lectura que se están dando en la región, considerando como pilares a la biblioteca pública y la escuela, gestándose en éstas los principales procesos para la formación de lectores.

\section{LA INSTITUCIÓN BIBLIOTECARIA EN LA AGENDA DE LAS POLÍTICAS DE LECTURA 2004}

Hasta el momento son ocho los países de la región latinoamericana y del Caribe que han formulado sus Planes Nacionales de Lectura: Argentina, Brasil, Cuba, Colombia, Ecuador, El Salvador, México, Venezuela, a los que se suman otros más que tienen programas de acción para el fomento de la lectura y el libro. En todos ellos, la participación de la institución bibliotecaria es fundamental en la formación de lectores y promoción de la lectura, como podemos constatar en los siguientes acuerdos de la Agenda de las Políticas de Lectura:

1. Crear y actualizar las bibliotecas y otros espacios de lectura en las escuelas públicas, como herramienta en la formación de alumnos y maestros lectores y escritores. 
2. Fomentar la creación y actualización de bibliotecas públicas, con el fin de que éstas puedan atender las necesidades de la lectura de la comunidad, con una oferta plural y pertinente de libros y otros soportes de información; asimismo, reconocer el papel fundamental que tiene la biblioteca en la formación de lectores y escritores.

3. Crear sistemas nacionales, regionales y municipales de bibliotecas públicas.

4. Crear, fortalecer y cualificar programas de formación inicial y continuar para que los docentes bibliotecarios y otros actores se tornen en mediadores de lectura.

5. Apoyar desde la biblioteca otros espacios de lectura: hospitales, cárceles, medios masivos de transporte, albergues, entre otros.

6. Incrementar programas de promoción de lectura dirigidos a la primera infancia y a la familia.

7. Contribuir a preservar la cultura y tradición oral, así como su fijación en lengua escrita.

8. Participar con toda la sociedad, en especial con grupos marginados social, económica y territorialmente.

9. Planes nacionales de la alfabetización, de fomento al libro y a la lectura y las bibliotecas.

10. Cambios de concepciones que obstaculizan el surgimiento de iniciativas de organización de la sociedad a favor de la lectura y la escritura.

\section{ACCIONES RECOMENDADAS POR LA AGENDA DE LAS POLÍTICAS DE LECTURA}

Por otro lado, entre las acciones recomendadas por la Agenda de las Políticas de Lectura, destacan las siguientes:

- Crear experiencias significativas de lectura y escritura que promuevan el uso de diversos materiales de lectura de calidad, en diferentes géneros y formatos. 
- Diseñar e implementar, desde las bibliotecas, programas permanentes de promoción de lectura y escritura dirigidos a distintos grupos de la comunidad.

- Fortalecer los vínculos de las bibliotecas con otras entidades que promuevan las diferentes manifestaciones culturales.

- Crear y actualizar las bibliotecas escolares y otros espacios de lectura en las escuelas públicas, como instrumento indispensable en la formación de alumnos y maestros lectores y productores de texto.

- Formar a los docentes y a los bibliotecarios como auténticos lectores y escritores de tal modo que puedan ser mediadores efectivos de la lectura y la escritura.

- Ampliar los alcances de los programas de educación intercultural bilingüe.

- Hacer valer el derecho a la lectura y la escritura de los niños, las niñas y los jóvenes afectados por algún tipo de discapacidad.

- Atender las recomendaciones del Manifiesto de la UNESCO que hace énfasis en la necesidad de implementar políticas para que la biblioteca escolar se convierta en un espacio de formación de lectores y escritores.

- Crear y fortalecer programas de formación de alumnos y docentes, como lectores y escritores.

- Formular proyectos de promoción de lectura en el ámbito escolar.

- Promover investigaciones sobre las problemáticas de lectura y escritura en las universidades y otros centros de estudio.

- Sistematización de las experiencias valiosas que realizan otros actores en diversos países de la región.

- Aprovechar los mecanismos de cooperación internacional existentes.

- Intercambio de experiencias en el interior de cada país.

- Crear, fortalecer y cualificar programas de formación inicial y continua, para que docentes, bibliotecarios y otros actores se conviertan en mediadores de lectura y escritura.

- Desarrollar experiencias de formación y actualización, a través de las cuales los mediadores continúen su proceso de formación y se reconozcan como lectores y productores de textos. 
- Incorporar la promoción de la lectura en los programas de formación profesional.

- Diseñar e implementar, desde las bibliotecas, programas permanentes de promoción de lectura y escritura dirigidos a distintos grupos de la comunidad.

\section{LA LECTURA EN LA IFLA}

La Federación Internacional de Asociaciones de Bibliotecarios e Instituciones (IFLA) tiene especial interés en la lectura; en consecuencia, cuenta con una sección destinada exclusivamente a este tema, la cual ha realizado conferencias y seminarios para abordar diferentes problemáticas, como puede apreciarse en el sitio web de la Sección de Lectura (IFLA Reading Section) ${ }^{3}$. Por su parte, la Sección de América Latina y el Caribe también ha impulsado proyectos destinados a fortalecer los programas de fomento a la lectura, varios de ellos con el apoyo del Programa ALP (Desarrollo de la Bibliotecología). En fecha reciente fue apoyado el proyecto Encuesta Internacional de Lectura para la Región de América Latina y el Caribe, el cual forma parte de una iniciativa global de la Sección de Lectura.

\section{ENCUESTA INTERNACIONAL DE LECTURA PARA LA REGIÓN DE} AMÉRICA LATINA Y EL CARIBE

\section{Misión}

Conocer y documentar la contribución de las bibliotecas públicas de América Latina y el Caribe en el desarrollo del lector y la promoción de la lectura a fin de formular programas de perfeccionamiento y actualización del personal bibliotecario; asimismo, para fundamentar las acciones de IFLA en cuanto al fortalecimiento de los programas en las escuelas de bibliotecología, asociaciones y bibliotecas para la solución de

3 IFLA. Reading Section [en línea] < http://www.ifla.org/VII/s33/index.htm> 
problemas de lectura y alfabetización de los ciudadanos. A la vez, tener elementos para participar en las políticas y programas de fomento a la lectura.

\section{Objetivo principal}

Proporcionar información representativa de la Región de América Latina y el Caribe para contribuir con la Encuesta Internacional de Lectura sobre el alcance que tiene en las comunidades y el personal de las bibliotecas públicas enfocado al desarrollo del lector y la promoción de la lectura, con el fin de identificar las necesidades de entrenamiento de bibliotecarios y de documentar los proyectos bibliotecarios en actividades de fomento a la lectura y desarrollo del lector.

Objetivos particulares

1) Realizar una investigación, mediante la encuesta entre las autoridades de las bibliotecas públicas, sobre las actividades que se llevan a cabo en relación con la alfabetización, promoción de la lectura y el desarrollo del lector.

2) Identificar las percepciones del personal con respecto al efecto del trabajo concentrado en el lector y la repercusión en el personal bibliotecario.

3) Utilizar la información recabada con el fin de ilustrar las percepciones del personal con respecto al efecto del trabajo concentrado en el lector, en su servicio y compartir ejemplos de una buena práctica.

4) Divulgar la información vía Internet.

\section{Justificación}

Este proyecto se encuentra enmarcado dentro de los pilares de IFLA en cuanto a: 


\section{Sociedad}

La lectura es una problemática para una sociedad como la actual que promueve:

- El uso eficiente de la información para transformarla en conocimiento.

- Una modalidad diferente de alfabetización que conduzca no sólo a la alfabetización permanente sino al aprendizaje para toda la vida.

- Alcanzar un dominio cada vez más perfeccionado de destrezas en la lectura y la escritura.

- Proporcionar las mismas oportunidades de acceso a la lectura y a la información de todos lo ciudadanos.

- Impedir que la lectura, la información y la educación sean factores de desigualdad y exclusión.

\section{Profesión}

Los planes y acciones dirigidas para fomentar el gusto por la lectura y el libro, así como la alfabetización, en donde la institución bibliotecaria está incorporada de manera muy importante, por lo cual es oportuno que las asociaciones nacionales, regionales e internacionales de bibliotecarios, las escuelas de Bibliotecología y los centros de investigación contribuyan para que las políticas se transformen en programas y acciones bibliotecarias, pero logrando lo indispensable en la preparación del personal bibliotecario para asegurar una participación contundente y de liderazgo de este sector.

\section{Miembros}

Acorde con el propósito de la Sección de Lectura de IFLA que ha propuesto desarrollar una Encuesta Internacional que en esencia pretende conocer el alcance de las actividades de fomento a la lectura y las implicaciones para la biblioteca pública, concretamente para el personal. Al 
mismo tiempo, identificar programas exitosos que puedan ser compartidos en la región y en otros países. La intención de esta encuesta es documentar las acciones bibliotecarias relacionadas con el fomento a la lectura con la finalidad de apoyar la planeación de servicios y la formación de bibliotecarios para que se incorporen en los planes nacionales de lectura.

\section{Beneficiarios}

La información que se desprenda de la Encuesta podrá ser de utilidad para:

- El sector de las bibliotecas públicas.

- Asociaciones y colegios de Bibliotecología

- IFLA, específicamente para las Secciones de America Latina y el Caribe, Lectura, Bibliotecas públicas, así como Educación y entrenamiento.

- La sociedad latinoamericana y caribeña en general.

\section{Responsable y colaboradores}

La responsable del proyecto es la Dra. Elsa M. Ramírez Leyva, investigadora del Centro Universitario de Investigaciones Bibliotecológicas (CUIB/UNAM), quien cuenta con el apoyo de la Lic. Martha Ibáñez Marmolejo, Técnico Académico del mismo Centro. Asimismo, se cuenta con la participación y colaboración de los siguientes profesionales en los distintos países de America Latina y del Caribe. 


\begin{tabular}{|c|c|}
\hline $\begin{array}{l}\text { Region Caribeña } \\
\text { Antillas Holandesas } \\
\text { Blanca Hodge } \\
\text { Directora de la biblioteca Philipsburg Jubilee } \\
\text { Ch. E.W. Vogsstreet } 12 \text { POB. } 2 \text { Philipsburg, } \\
\text { St. Maarten, Netherlands Antilles } \\
\text { Tel. (599)(542) } 2970 \\
\text { Fax. (599)(542)5805 } \\
\text { blahodge@sintmaarten.net }\end{array}$ & $\begin{array}{l}\text { Argentina } \\
\text { Ana M. Peruchena Zimmermann } \\
\text { Presidenta de ABGRA } \\
\text { Tucumán 1424, piso 8, Dpto. D } \\
\text { C1050AAB Buenos Aires, Argentina } \\
\text { Tel. (54)(11)43715269 / } 43730571 \\
\text { Fax. (54)(11)43715269 } \\
\text { secretaria@abgra.org.ar } \\
\text { aperuchena@abfra.org.ar }\end{array}$ \\
\hline $\begin{array}{l}\text { Bolivia } \\
\text { Lic. Hugo B. Morales Bellido } \\
\text { Presidente del Colegio de Profesionales en } \\
\text { Ciencias } \\
\text { de la Información de Bolivia } \\
\text { Calle Batallón Colorados No. 24, Edif. "El } \\
\text { Condor" Planta Baja, Oficina No. } 5 \\
\text { Tel. } 2440263 \\
\text { Tel. casa } 71551997 \\
\text { Casilla } 12148 \text { Correo Central, La Paz Bolivia. } \\
\text { hmoralesbellido@ hotmail.com }\end{array}$ & $\begin{array}{l}\text { Brasil } \\
\text { Marcia Rosetto } \\
\text { Presidenta de FEBAB } \\
\text { Rua Avanhandava 40, cj.108/110, } 1^{\circ} \text { Andar } \\
\text { 01306-000 Sao Paulo, SP, Brazil } \\
\text { Tel. (55)(11)32579979 } \\
\text { Fax. (55)(11)32579979 } \\
\text { mrosetto@usp.br } \\
\text { febab@febab.org.br }\end{array}$ \\
\hline $\begin{array}{l}\text { Brasil } \\
\text { Ana Ligia Medeiros } \\
\text { Directora de la Bibliotea Pública del Estado de } \\
\text { Río de Janeiro (BIPERJ) } \\
\text { Av. Presidente Vargas, } 1261 \text { 20071-004 Rio } \\
\text { de Janeiro, RJ Brazil } \\
\text { Tel. +(55)(21) } 33225330 \\
\text { Fax. +(55)(21) 33225733 } \\
\text { http://www.bperj.rj.gov.br/Principal.html } \\
\text { bibliotecapublica@bperj.rj.gov.br }\end{array}$ & $\begin{array}{l}\text { Brasil } \\
\text { Elizabeth M. Ramos de Carvalho } \\
\text { iflalac@mls.com } \\
\text { Celia Ribeiro Zaher } \\
\text { Director, Centro de Processos Técnicos, } \\
\text { Fundaçao Biblioteca Nacional } \\
\text { czaher@bn.br }\end{array}$ \\
\hline $\begin{array}{l}\text { Chile } \\
\text { Nivia Palma Manríquez } \\
\text { Directora de Bibliotecas, Archivos y Museos } \\
\text { Alameda } 651 \text { Piso } 2 \text { Santiago, Chile } \\
\text { http://www.dibam.cl/home.asp } \\
\text { dirección@dibam.cl } \\
\text { Tel. } 3605271\end{array}$ & $\begin{array}{l}\text { Chile } \\
\text { Ricardo López Muñoz } \\
\text { Subdirector de Bibliotecas Públicas de Chile } \\
\text { Alameda } 651 \text { Piso } 2 \text { Santiago, Chile } \\
\text { rlopez@sbp.cl } \\
\text { Tel. } 6742430\end{array}$ \\
\hline
\end{tabular}




\begin{tabular}{|c|c|}
\hline $\begin{array}{l}\text { Costa Rica } \\
\text { Msc. Saray Córdoba González } \\
\text { Coordinadora de Investigación } \\
\text { Sede de Occidente, Universidad de Costa Rica } \\
\text { Apdo. 111-4250 } \\
\text { Ciudad Universitaria Carlos Monge Alfaro } \\
\text { Tel. 506-4379835 506-4455122 } \\
\text { Fax: 506-4456005 } \\
\text { scordoba@cariari.ucr.ac.cr }\end{array}$ & $\begin{array}{l}\text { Costa Rica } \\
\text { Alice Miranda } \\
\text { Universidad Nacional de Costa Rica Escuela de } \\
\text { Bibliotecología, Documentación e Información } \\
\text { Facultad de Filososfía y Letras } \\
\text { amiranda@una.ac.cr } \\
\text { Tel } 5624080 \\
\text { Fax. } 5624082\end{array}$ \\
\hline $\begin{array}{l}\text { Colombia } \\
\text { Gloria M. Rodríguez } \\
\text { Biblioteca COMFENALCO } \\
\text { Calle } 51 \text { No. 45-37 } \\
\text { Medellín, Colombia } \\
\text { Tel. (574) } 5121902 \\
\text { Fax. (574) } 5123949 \\
\text { gmrodriguez@intic.net }\end{array}$ & $\begin{array}{l}\text { Cuba } \\
\text { Emilio Setien } \\
\text { Universidad de La Habana, Departamento de } \\
\text { Bibliotecología y Ciencia de la Información } \\
\text { Facultad de Comunicación, Calle G \# 506e } 23 \\
\text { y 21, Vedado, Cuba } \\
\text { esetien@infomed.sld.cu } \\
\text { Tel. } 8326583 \\
\quad 8326584\end{array}$ \\
\hline $\begin{array}{l}\text { Ecuador } \\
\text { Lic. Mercedes Falconi } \\
\text { Directora del Centro Ecuatoriano de Literatura } \\
\text { Infantil y Juvenil (CEDLIJ) } \\
\text { Ciudadela la Granja Av. Mariana de Jesús Ac- } \\
\text { ceso } 37-38 \text { Bloque } 37 \text { dep. 21, Quito, Ecuador } \\
\text { Tel. (593) } 2433535 \\
\text { Fax. (593) 2451347 } \\
\text { borges@uio.satnet.net }\end{array}$ & $\begin{array}{l}\text { El Salvador } \\
\text { Lic. Olinda Estela Gómez Morán } \\
\text { Biblioteca "Dr. José Gustavo Guerrero" } \\
\text { Ministerio de Relaciones Exteriores } \\
\text { Final } 17 \text { Av. Norte, Edificio No. 4, 1a. planta. } \\
\text { Centro de Gobierno } \\
\text { Tel. 271-3266 ext. } 329 \text { y } 277 \\
\quad 231-1378 \\
\text { ogomez@rree.gob.sv }\end{array}$ \\
\hline $\begin{array}{l}\text { México } \\
\text { Dra. Elsa Margarita Ramírez Leyva } \\
\text { Investigadora del Centro Universitario de } \\
\text { Investigaciones Bibliotecológicas (CUIB/ } \\
\text { UNAM) } \\
\text { Torre II de Humanidades, piso 11, Circuito } \\
\text { Interior } \\
\text { Ciudad Universitaria C.P. } 04510 \\
\text { Tel. } 56230348 \\
\text { Fax. } 55507461 \\
\text { eramirez@servidor.unam.mx }\end{array}$ & $\begin{array}{l}\text { Panamá } \\
\text { Dr. Octavio Castillo Sánchez } \\
\text { Edificio Principal del Campus Universitario } \\
\text { "Octavio Méndez Pereira", el Cangrejo, } \\
\text { Panamá } \\
\text { Universidad de Panamá } \\
\text { biblis2@ancon.up.ac.pa }\end{array}$ \\
\hline
\end{tabular}


Bibliotecas y Bibliotecología en América Latina y el Caribe...

\begin{tabular}{|c|c|}
\hline $\begin{array}{l}\text { Paraguay } \\
\text { Emilce Sena } \\
\text { AGRIAP } \\
\text { emilcesena@yahoo.es } \\
\text { abigrap@pol.una.py }\end{array}$ & $\begin{array}{l}\text { Perú } \\
\text { César Augusto Castro Aliaga } \\
\text { Av. San Borja Norte No } 379 \text { - Dpto. } 201 \text { - San } \\
\text { Borja, Lima 41-Perú. } \\
\text { Telf. 511-2237230 } \\
\text { cel. 511-98096141 } \\
\text { castroaliaga@hotmail.com }\end{array}$ \\
\hline $\begin{array}{l}\text { Perú } \\
\text { Doris I. Samanez Alzamora } \\
\text { Pontificia Universidad Católica del Perú. } \\
\text { Oficina de Procesos Técnicos } \\
\text { Av. Universitaria Cuadra } 18 \text { s/n. } \\
\text { San Miguel, Lima } 32 \text { - Apartado 1761, Perú. } \\
\text { (Tercer piso anexo 3423) } \\
\text { samanezalzamora@ @otmail.com } \\
\text { dsamanez@pucp.edu.pe } \\
\text { Tel. (51-1) } 6262000 \text { Fax: (51-1) } 6262861\end{array}$ & $\begin{array}{l}\text { Puerto Rico } \\
\text { Victor Federico Torres } \\
\text { Oficial de Desarrollo de Colecciones/ Collec- } \\
\text { tion Development Officer } \\
\text { Sistema de Bibliotecas } \\
\text { Universidad de Puerto Rico-Río Piedras } \\
\text { San Juan, Puerto Rico 00931 } \\
\text { Tel. (787) 764-00 00, ext. } 7920 \\
\text { Fax. (787) 763-56 85 } \\
\text { vtorres@upracd.upr.clu.edu }\end{array}$ \\
\hline $\begin{array}{l}\text { Uruguay } \\
\text { Lic. Ana María Cherro } \\
\text { Sistema Nacional de Información. Ministerio } \\
\text { de Educación y Cultura } \\
25 \text { de Mayo 520. Montevideo, Uruguay } \\
\text { Tel. (598-2)9166887 } \\
\text { Fax. (598-2)9168495 } \\
\text { sni@adinet.com.uy } \\
\text { viche41@hotmail.com } \\
\text { http://chana.mec.gub.uy/arch_geral/ricytu. } \\
\text { htm }\end{array}$ & $\begin{array}{l}\text { Venezuela } \\
\text { Mtra.María Elena Zapata } \\
\text { Biblioteca Nacional de Venezuela } \\
\text { Las Mercedes, Calle París } \\
\text { Edificio Macanao } \\
\text { piso 2, Apartado } 6525 \\
\text { Caracas } 1010 \\
\text { Venezuela } \\
\text { Fax: (58-02) } 9933093\end{array}$ \\
\hline
\end{tabular}




\title{
Educación bilingüe intercultural y servicios bibliotecarios en los pueblos indígenas del Perú
}

\author{
César Castro Aliaga \\ Comité Permanente de la Sección de América Latina y el Caribe, \\ Federación Internacional de Asociaciones e Instituciones Bibliotecarias
}

L

a mayoría de las experiencias sobre servicios bibliotecarios en pueblos indígenas, tanto en el Perú como en otros países de América Latina, están relacionadas estrechamente con proyectos de carácter educativo, específicamente con la educación bilingüe intercultural. La Biblioteca Magüta de los indígenas Ticuna del Brasil (Estado de Amazonas), sirve de apoyo a la formación de profesores indígenas; el proyecto venezolano "Libro Viviente" (persona poseedora de conocimientos y saberes) es la fuente para la producción de materiales educativos destinados también a los pueblos indígenas, por citar sólo dos experiencias. Sin duda, la expansión de la educación bilingüe intercultural en los países con población indígena está favoreciendo la difusión de los servicios bibliotecarios en contextos indígenas, excluidos históricamente del acceso a esos y otros servicios básicos.

A la luz de estos resultados, se puede sostener que los servicios bibliotecarios integrados en el proceso educativo de la población indígena, no sólo permiten el acceso a la información y al conocimiento, sino también fortalecen el proceso educativo, asegurando la formación de lectores que posean las habilidades y destrezas para utilizar tanto recursos producidos localmente en lengua indígena, como los producidos en otras lenguas y en otros contextos, pero relevantes a 
sus necesidades e intereses. De esta manera se hace patente una educación realmente intercultural.

Por todo lo dicho, la promoción de servicios bibliotecarios no debiera desaprovechar el espacio que ofrece la educación bilingüe intercultural, la que actualmente cuenta con amplio apoyo político y social en la mayoría de los países de la región.

Partiendo de la premisa de que "si la escuela es bilingüe e intercultural, la biblioteca que sirve de apoyo, también debe seguir esa propuesta" (Bessa, 2001), en el presente trabajo se proponen algunas acciones para la promoción y desarrollo de los servicios bibliotecarios y de información en los pueblos indígenas, conscientes de que un proyecto integrado entre Educación Bilingüe Intercultural y Biblioteca Indígena fortalece el proceso educativo y cultural de la comunidad en su conjunto. De esta forma, los proyectos bibliotecarios alcanzarían una mayor consistencia y una mayor cobertura, pues no sólo cubrirían a la población escolar, sino también a la población en general.

\section{EDUCACIÓN BILINGÜE INTERCULTURAL}

\section{El escenario peruano}

El Perú es uno de los tres países de América Latina, junto a Guatemala y Ecuador, que cuenta con mayor población indígena. Aun cuando no hay cifras oficiales, es probable que esta población alcance, aproximadamente, 9 millones de habitantes pertenecientes a unos 48 grupos étnicos amazónicos y 1200 comunidades andinas. Asimismo, a nivel nacional perviven 16 familias lingüísticas, de las cuales 14 son amazónicas y tres andinas (Pozzi Scot, 2000). El Perú es un país pluricultural y multilingüe en toda su extensión.

La población nacional, según el censo del 2005, es de 27219264 habitantes, distribuida en tres grandes regiones: Costa, Sierra y Selva. De ellas, la primera alberga al 50\% de la población, debido sobre todo a las grandes migraciones de las últimas décadas. La Selva, en cambio, aunque es la más extensa, alberga sólo el 10\% de la población, incluidos los grupos étnicos amazónicos. La Sierra, el gran trapecio andino, 
está ocupada por el $40 \%$ de la población, donde se encuentran incluidas las poblaciones quechua y aima.

En el plano educativo, en el año 2004, la población escolar alcanzaba 85598605 matriculados, de los cuales cerca del 30\% correspondían a zonas rurales, porcentaje que es aún mayor en los casos de la educación inicial (34\%) y la educación primaria (37\%).

Este es pues el escenario en el que, progresivamente, se viene impulsando la educación bilingüe intercultural, como un proceso orientado fomentar el uso de las lenguas indígenas como medio de comunicación y vehículo de aprendizaje.

\section{Antecedentes}

En 1953, ya la UNESCO sostenía que "el mejor medio para la enseñanza de un niño es su lengua materna". Pues bien, los orígenes de la educación bilingüe en el Perú también son de esa época, como se puede apreciar en las siguientes referencias:

1946 Inicios de la educación bilingüe, con la participación del Instituto Lingüístico de Verano, en la Amazonía peruana.

1964 Plan de Fomento lingüístico, emprendido por la Universidad Nacional Mayor de San Marcos, a través de su Instituto de Investigación en Lingüística Aplicada, CILA.

1975 Proyecto de Educación Bilingüe del Alto Napo (PEBIAN).

1976 Proyecto Experimental de Educación Bilingüe de Puno, emprendido por el Ministerio de Educación del Perú con los auspicios del Gobierno de la República Alemana.

1981 Educación Bilingüe en el Río Tambo, promovido por el Centro Amazónico de Antropología Práctica, CAAAP.

En los últimos años, el Ministerio de Educación ha tomado una serie de medidas para impulsar y fortalecer la educación bilingüe intercultural, que se han plasmado, progresivamente, en: Política de Educación Bilingüe Intercultural (1989); Política Nacional de Educación Intercultural y Educación Bilingüe Intercultural (1991); y Política Nacional de 
Lenguas y Culturas en la Educación (2001). Todo ello, finalmente se consolidó en la nueva Ley General de Educación de 2003, donde se "reconoce y garantiza el derecho de los pueblos indígenas a una educación en condiciones de igualdad con el resto de la comunidad nacional".

En este largo proceso, se pueden distinguir claramente dos etapas:

- Primera: Educación bilingüe, concebida como "una propuesta de transición en la que la meta era que el niño aprendiera castellano" (Vigil, 2003, p. 247).

- Segunda: Educación bilingüe intercultural, EBI, concebida "como aquella que además de formar sujetos bilingües con óptima competencia comunicativa en su lengua materna y en castellano, posibilita la identificación con su cultura de origen y el reconocimiento de otras culturas que podrían constituir un valioso aporte para el mejoramiento de su nivel de vida y de su comunidad, enriqueciendo así su propia cultura”. (Ministerio de Educación, 1989).

Principales características de la EBI:

Mencionaremos algunas características tomadas de las propias normas del Ministerio de Educación y de algunos aportes de los especialistas en el tema:

a) Incorpora a la práctica pedagógica las características y valores socio-lingüístico culturales de los pueblos indígenas;

b) Recupera y valora la cultura y su identidad como base del desarrollo integral de la persona;

c) Consolida el uso de las lenguas autóctonas como medios de expresión, desarrollo cultural y autoafirmación;

d) Vincula la cultura ancestral con conocimientos de otras culturas, logrando así un proceso dinámico de interculturalidad.

e) Garantiza el aprendizaje en la lengua materna de los educandos y del castellano como segunda lengua. 
f) Determina la obligación de los docentes de dominar, tanto la lengua originaria de la zona donde laboran, como el castellano.

g) Asegura la participación de los miembros de los pueblos indígenas en la formulación y ejecución de programas de educación para formar equipos capaces de asumir progresivamente la gestión de dichos programas.

h) Preserva las lenguas de los pueblos indígenas y promueve su desarrollo y práctica.

i) Promueve el diálogo intercultural y la toma de conciencia de los derechos de los pueblos indígenas, y de otras comunidades nacionales y extranjeras.

g) Incorpora la historia de los pueblos, sus conocimientos y tecnologías, sistemas de valores y aspiraciones sociales y económicas.

\section{Resultados}

Hoy en día, muy pocos dudan de las ventajas de la educación bilingüe intercultural en: el fomento del uso de las lenguas autóctonas; la preservación de la cultura local; el aprendizaje de la segunda lengua; y su carácter participativo y de interacción basado en el diálogo intercultural. Son los propios docentes quienes reconocen que:

el niño que estudia su propia cultura e idioma en la escuela cobra seguridad en sí mismo, adquiere las habilidades cognoscitivas necesarias para su crecimiento intelectual equilibrado. Conociendo la gramática de su propia lengua y los valores de su propia cultura, avanza con seguridad en el aprendizaje de una segunda lengua y cultura, llegando así, a compartir lo mejor de ambos mundos que están a su alcance. (Zavala, 2001)

Sin embargo, la educación bilingüe intercultural en el Perú tiene una serie de dificultades. Por un lado, su cobertura es aún limitada, pues según estimaciones, apenas alcanza al $40 \%$ de la población escolar de la educación primaria y al $20 \%$ de educación inicial. De otro lado, ahí donde se da, existen innumerables problemas, económicos, 
sociales y de orden técnico pedagógico, entre otros, que se traducen en la falta de una adecuada capacitación de los maestros, escasez de materiales en lengua materna y contenidos locales, por citar algunos aspectos. Concretamente, en lo que atañe a materiales educativos, en la mayoría de las escuelas indígenas el texto escolar, cuando llega, es el único material escrito con que cuenta el alumno; la creación de materiales a partir de contenidos locales, de las tradiciones orales, costumbres, mitos, etcétera, todavía no se da en niveles adecuados y la ausencia de bibliotecas es casi generalizada en las escuelas que aplican EBI. Del mismo modo, sobre todo en el mundo andino, a estas carencias se suma la actitud de los padres de familia que rechazan el uso de la lengua materna como medio de enseñanza, favoreciendo a la lengua castellana.

Frente a los diferentes problemas, la Dirección Nacional de Educación Bilingüe Intercultural del Ministerio de Educación, órgano responsable de definir la política nacional de educación bilingüe intercultural, así como de orientar y coordinar la aplicación de dicha política en todos los niveles del sistema educativo, viene impulsando una serie de acciones como: capacitación de docentes, elaboración de guías técnico pedagógicas para docentes, formación de equipos de docentes (traductores) para la elaboración de materiales, diseño y desarrollo de proyectos sobre nuevas tecnologías de información y comunicación, elaboración de materiales en soporte electrónico para las escuelas bilingües interculturales, así como la ejecución de campañas interculturales para la revaloración de los conocimientos y saberes de los pueblos indígenas, entre otras. De todo ello debemos destacar la elaboración de material impreso (196 títulos en los últimos años) destinado a los alumnos, docentes y a la biblioteca de aula, lo que puede ser el germen para la formación de la biblioteca indígena intercultural. (Ver Anexo 1) 


\section{RELACIÓN DE LA EDUCACIÓN BILINGÜE CON LOS SERVICIOS BIBLIOTECARIOS}

Como resultado del encuentro ${ }^{1}$ realizado sobre el tema en México en el 2000, ya se proponía un perfil de la biblioteca indígena, destacando su carácter interétnico y su rol como centro de documentación e información, en relación con el sistema educativo formal e informal, la producción de materiales pertinentes, así como la investigación y recopilación del patrimonio cultural de los pueblos indígenas. Adicionalmente, en el Seminario Internacional sobre Servicios Bibliotecarios y de Información en los pueblos indígenas de América Latina, realizado en Lima en el año 2002, se sugiere enriquecer este perfil dentro una concepción más amplia de centro de información, que incluya elementos como oralidad, escritura e imagen. Todo ello nos permite vislumbrar un modelo de biblioteca indígena caracterizado, en esencia, por su función educativa, pero también de preservación y difusión, en un contexto marcado por la interculturalidad. Es decir, donde la biblioteca sea al mismo tiempo un centro de recursos informativos variados, generados por la escuela y la comunidad, en lengua autóctona, y un centro receptor de aquellos materiales producidos en otras lenguas y otros contextos, cuyo contenido sea pertinente a las necesidades e intereses de la población en su conjunto y que le permitan usufructuar las ventajas que ofrecen los modernos sistemas de información y comunicación. De esta forma, la biblioteca indígena, en cualquier contexto, debe ser esencialmente una biblioteca intercultural.

En otras palabras, se propone una biblioteca intercultural que actúe como un centro que organice todo tipo de materiales, de origen local y externo, para el servicio educativo y el desarrollo cultural de la población en general; que igualmente, organice, preserve y difunda la memoria colectiva de la comunidad, revitalizando la identidad étnica, lingüística y cultural y se proyecte a la sociedad en su conjunto.

De lo tratado hasta el momento, se pueden extraer las siguientes conclusiones:

1 Encuentro Latinoamericano sobre Atención Bibliotecaria a las Comunidades Indígenas, Ciudad de México, CUIB-UNAM/IFLA, del 15 al 17 de noviembre de 2000. 
1) Gracias al impulso de la educación bilingüe, se abre un nuevo escenario para la promoción de la biblioteca indígena, que siendo parte de la escuela, también debe ser bilingüe e intercultural, y por lo tanto, comparten objetivos.

2) Su ubicación en el contexto de la escuela, permite a la biblioteca participar activamente en la formación y desarrollo de las habilidades lectoras perdurables, estimulando la producción y uso de materiales de diferentes soportes, en lengua materna y castellano, fortaleciendo así la acción educativa en general de la escuela.

3) La biblioteca, si bien es gestada en el seno de la escuela indígena, en su creación y desarrollo participan los docentes y alumnos y la población en general, como parte de su proceso organizativo y reivindicativo. En estos tiempos, es frecuente que las organizaciones indígenas, como parte de sus reivindicaciones, incluyan la implementación de bibliotecas en sus escuelas.

4) La biblioteca bilingüe e intercultural, desde su ubicación en la escuela, proyecta sus servicios a los demás miembros de la comunidad, puesto que en los pueblos indígenas la escuela es participativa y abierta a la población, sin barreras físicas ni de otra índole con la comunidad.

5) La biblioteca indígena también puede ayudar a la población a conectarse con el mundo de la información digital, no sólo para obtener información según sus necesidades, sino también para difundir a través de la red su bagaje de conocimientos y saberes, haciéndose patente el principio de interculturalidad. A este respecto, varios pueblos indígenas de la Amazonía vienen haciendo uso de las tecnologías de la información y comunicación, siendo la experiencia más reciente la de la Comunidad de Marankiari Bajo (Departamento de Junín).

En suma, las bibliotecas indígenas, generadas por el impulso de las escuelas bilingües interculturales, ayudan de manera efectiva a la construcción de las bases de la Sociedad de la Información, facilitando el acceso a la población en general a los diferentes tipos de materiales, incluso a las redes de información. 


\section{INTERCULTURALIDAD: UNA META DE LA ESCUELA Y LA BIBLIOTECA.}

La interculturalidad es un tema sobre el cual debemos reflexionar, pues no se limita al campo de la educación, como pareciera entenderse hasta aquí, sino que:

se encuentra presente en las relaciones humanas en general, como una alternativa frente al etnocentrismo y los intentos de homogeneización de un modelo cultural unitario, urbano y castellano hablante; es una propuesta de derecho a la diversidad y el respeto a la diferencia.

Es decir, es:

una actitud de apertura, una apuesta por el respeto a la pluralidad de nacionalidades y a la heterogeneidad de formas de vida (Heise, 1994) y viene a ser el eje de nuestras acciones y se aplica perfectamente a la biblioteca Indígena en funciones, que se convierte en un escenario interactivo, donde ambas culturas se recrean y se enriquecen,

donde el usuario recibe, pero también da y participa en su accionar de manera auténtica y espontánea, estimulado del dinamismo que surge del servicio bibliotecario. De esta manera, la escuela y su biblioteca pueden forjar al ciudadano intercultural:

con actitudes personales positivas hacia la diversidad, abierto a aprender de otros estilos de vida y dispuestos a considerar cómo se ven las cosas desde el punto de vista de la otra gente (Valiente y Tubbino, 2001).

La misma reunión donde se expuso el presente documento, fue una expresión auténtica de interculturalidad, donde bibliotecarios y trabajadores de la información del Estado de Ceara, Brasil y de otros países de la región, por decisión propia, aceptamos reunirnos, para compartir nuestras visiones, nuestras experiencias y nuestros sueños, respetando nuestras identidades, pero con el mismo objetivo: mejorar y ampliar los puntos de acceso a la información y el conocimiento a 
todos los ciudadanos, para hacer plena la vigencia de la Sociedad de la Información.

PROPUESTAS PARA EL FORTALECIMIENTO DE LAS BIBLIOTECAS INDÍGENAS

Producción y difusión de materiales en lenguas indígenas

- Que se diseñen y ejecuten programas de producción de materiales de lectura y de información en lenguas indígenas, a partir de las tradiciones orales, mitos y costumbres para atender las necesidades de la escuela y de la población en general, como un medio para recuperar, preservar y difundir el patrimonio cultural de los pueblos indígenas.

- Que como un esfuerzo prioritario se identifique, catalogue y se ponga en la red todo material informativo producido en lenguas autóctonas, sin restricciones de la institución que lo generó, incluyendo los soportes digitales, para ponerlos a disposición de las poblaciones indígenas.

\section{Proyecto regional}

- Que se prepare un proyecto regional de impulso a las bibliotecas indígenas para América Latina, que descanse sobre las experiencias más relevantes en la materia a nivel de todos los países de la región, que incluya aspectos como: diseño y puesta en marcha del modelo de servicios; formación de recursos humanos; producción de materiales; lectura y habilidades informacionales; utilización de tecnologías de la información y comunicación; preservación y difusión del patrimonio cultural de los pueblos indígenas, investigación en temas que atañen a la biblioteca indígena intercultural, entre otros, que nos permita vislumbrar el desarrollo de esta modalidad de servicios en un horizonte de mediano y largo plazos, en respuesta a los desafíos de la Sociedad de la Información. 
Sociedad de la Información

- Que dentro de los programas de la Sociedad de la Información, se incluyan propuestas orientadas a impulsar de manera decidida el modelo de biblioteca intercultural, con el fin de favorecer el acceso a la información a la población indígena, que en la mayoría de los países se encuentran excluidas de estos servicios; tampoco esta población, mayoritariamente oral, ha recibido el suficiente entrenamiento para la búsqueda y la utilización de la información en soportes no convencionales.

- Que se apoye la conformación de bibliotecas indígenas con componentes tecnológicos modernos, puesto que los pueblos indígenas valoran las ventajas de estas tecnologías y, en muchos casos, tanto en el Perú como en otros países, ya lo vienen usando en forma limitada; asimismo, que sea un sistema de información intercultural, donde no sólo se pueda encontrar información externa, sino también la información y los conocimientos de los pueblos indígenas que, hasta hoy, han dado muestras de desprendimiento y solidaridad, al poner a disposición de la sociedad muchos de sus conocimientos y saberes.

\section{REFLEXIONES FINALES}

Todo hace suponer que si seguimos al ritmo de ahora, el proceso de construcción de la Sociedad de la Información será muy lento y un porcentaje muy alto de la población indígena no podrá participar ni compartir los beneficios que acarrea su implantación. En este sentido, se deben hacer todos los esfuerzos posibles para que la biblioteca indígena se convierta en un modelo de sistema de información, forjada por los propios indígenas, integrada a otros programas sociales como la educación bilingüe intercultural, para potenciar y optimizar los recursos que, como sabemos, siempre serán escasos cuando se trata de favorecer un sector social con altos índices de exclusión, como los pueblos indígenas. 


\section{BIBLIOGRAFÍA}

Actas del V Congreso Latinoamericano de Educación Intercultural Bilingüe: realidad multilingüe y desafío intercultural, ciudadanía, política y educación / Roberto Zariquiey (editor)._Lima: Pontificia Universidad Católica del Perú, Ministerio de Educación, Cooperación Técnica Alemana, 2003. 523 p.

Bessa Freire, José R. "La escuela indígena y la biblioteca intercultural en Brasil". En: Encuentro Latinoamericano sobre la Atención Bibliotecaria a las Comunidades Indígenas: memoria. México: Universidad Nacional Autónoma de México, Centro Universitario de Investigaciones Bibliotecológicas, Federación Internacional de Asociaciones de Bibliotecarios e Instituciones, 2001. pp .27-40

Construir la escuela intercultural: reflexiones y propuestas para trabajar la diversidad étnica y cultural / Miguel Angel Essomba (coord.).- Barcelona: Graó, 2002 . 196 p. (Biblioteca de Aula).

Encuentro Latinoamericano sobre la Atención Bibliotecaria a las Comunidades Indígenas (México, D.F.: 2000). Memoria del encuentro, 15-17 de noviembre de 2000 en la Ciudad de México / comp. María del Rocío Graniel Parra.-México: UNAM, Centro Universitario de Investigaciones Bibliotecológicas; Federación Internacional de Asociaciones de Bibliotecarios e Instituciones, 2001. 190 p.

Heise, María y otros. Interculturalidad: un desafío / María Heise, Fidel Tubito y Wilfredo Ardito.-Lima: Centro Amazónico de Antropología y Aplicación Práctica, 1994.

Lozano Vallejo, Ruth. Análisis de la problemática de la educación bilingüe en la Amazonía Peruana; documento de trabajo $N^{\circ}$ 4.-Cuzco: Defensoría del Pueblo, Adjuntía para los Derechos Humanos y las Personas con Discapacidad, 2000. $180 \mathrm{p}$. 
Memorias del Seminario Internacional sobre Acceso a los Servicios Bibliotecarios y de Información en los Pueblos Indígenas de América Latina (Lima, 2002). Lima: IFLA/ALP y Centro Amazónico de Antropología y Aplicación Práctica, CAAAP, 2003.

Ministerio de Educación. Dirección General de Educación Bilingüe Intercultural. Lineamientos de Política. Lima: Ministerio de Educación, 1989.

Pozzi-Escot, Inés. El multilingüismo en el Perú. Cuzco: Centro de Estudios Regionales Andinos "Bartolomé de las Casas”; Programa de Formación en Educación Intercultural Bilingüe para los Países Andinos, 1998. 310 p.

Programa de estudios de educación inicial: currículo alternativo popular intercultural -bilingüe._La Paz: Fé y Alegría, Movimiento de Educación Popular Integral y de Promoción Social, 1998. 107 p.

Rivero, José. Educación y exclusión en América Latina: reformas en tiempos de globalización.-Lima: Tarea, 1999. $438 \mathrm{p}$.

Valiente, Teresa y Tubino, Fidel. Introducción a las Actas del $V$ Congreso Latinoamericano de Educación Intercultural Bilingüe "Realidad Multilingüe y Desafío Intercultural: Ciudadanía, Cultura y Educación" / Roberto Zariquiey, editor.-Lima: Cooperación Técnica Alemana, 2003. pp. 17-44.

Vasquez H., Enrique. Buscando el bienestar de los pobres: ¿cuán lejos estamos?. Lima: Universidad del Pacífico, 2003. $307 \mathrm{p}$.

Vega Centeno, Imelda. "La tradición oral como fuente para el estudio del imaginario de género".-En: Interculturación, Lima, julio-diciembre 2003, Año 9, No. 2. 
Vigil, Nila. "Enseñanza de castellano como lengua materna en un modelo de educación intercultural". En: Actas del $V$ Congreso Latinoamericano de Educación Intercultural Bilingüe "Realidad Multilingüe y Desafío Intercultural: Ciudadanía, Cultura y Educación" / Roberto Zariquiey, editor-_Lima: Cooperación Técnica Alemana. (2003). pp. 247-261.

Zavala, Virginia. Oralidad y escritura en la educación bilingüe (a propósito de interculturalidad)._Lima: Ministerio de Educación, Programa Especial MECEP, Cooperación Técnica Alemana, GTZ, Cooperación Financiera, República Federal de Alemana, KFW, 2001. 50 p. (Serie: Educación Bilingüe Intercultural)

Zúñiga Castillo, Madeleine. Interculturalidad y educación en el Perú / Madeleine Zúñiga y Juan Ansión.-Lima: Foro Educativo, 1977. 68 p. 
Educación bilingüe intercultural y servicios bibliotecarios...

\section{ANEXO 1}

Material bibliográfico producido para el Programa EBI - 2003-2004

\begin{tabular}{|l|c|c|c|c|}
\hline \multirow{2}{*}{ Lengua } & \multirow{2}{*}{ Total títulos } & \multicolumn{3}{|c|}{ Distribución según uso } \\
\cline { 3 - 5 } & & Alumno & Docente & Biblioteca* $^{*}$ \\
\hline Achuar & 06 & 04 & -- & 02 \\
\hline Aguaruna & 21 & 08 & 02 & 11 \\
\hline Aimara & 26 & 12 & 02 & 12 \\
\hline Asháninka & 11 & 08 & 02 & 01 \\
\hline Bora & 05 & 04 & -- & 01 \\
\hline Huambisa & 05 & 04 & 01 & -- \\
\hline Huitoto & 01 & -- & -- & 01 \\
\hline Machiguenga & 04 & 04 & -- & -- \\
\hline Matsés & 04 & 04 & -- & -- \\
\hline Quechua & 81 & 46 & 10 & 01 \\
\hline Shipibo & 09 & 05 & 02 & 02 \\
\hline Castellano & 15 & 02 & 11 & 01 \\
\hline Chayahuita & 07 & 04 & 02 & 01 \\
\hline Cocama & 01 & -- & -- & 56 \\
\hline \multicolumn{1}{|c|}{ Total } & $\mathbf{1 9 6}$ & $\mathbf{1 0 5}$ & $\mathbf{3 2}$ & \\
\hline
\end{tabular}

Fuente: Dirección Nacional de Educación Bilingüe Intercultural 

Bibliotecas y Bibliotecología en América Latina y el Caribe: Un acercamiento. La edición consta de 300 ejemplares. Cuidado de la edición Zindy Elizabeth Rodríguez Tamayo. Formación editorial, Mario Ocampo Chávez. Centro Universitario de Investigaciones Bibliotecológicas. Fue impreso en papel cultural de 90 gr. en Robles Hnos. y Asoc., S.A de C.V. ubicados en Heriberto Frías 1439-404 Col. del Valle, México, D. F. Se terminó de imprimir en el mes de agosto de 2007. 